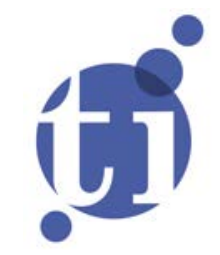

\title{
An Econometric Analysis of ETF and ETF Futures in Financial and Energy Markets using Generated Regressors
}

Chia-Lin Chang ${ }^{\prime}$

Michael McAleer ${ }^{2}$

Chien-Hsun Wang 3

${ }^{\prime}$ National Chung Hsing University, Taiwan;

2 National Tsing Hua University, Taiwan; Erasmus School of Economics, Erasmus University Rotterdam; Complutense University of Madrid, Spain;

${ }^{3}$ National Tsing Hua University, Taiwan. 
Tinbergen Institute is the graduate school and research institute in economics of Erasmus University Rotterdam, the University of Amsterdam and VU University Amsterdam.

More TI discussion papers can be downloaded at http://www.tinbergen.nl

Tinbergen Institute has two locations:

Tinbergen Institute Amsterdam

Gustav Mahlerplein 117

1082 MS Amsterdam

The Netherlands

Tel.: +31(0)20525 1600

Tinbergen Institute Rotterdam

Burg. Oudlaan 50

3062 PA Rotterdam

The Netherlands

Tel.: +31(0)10 4088900

Fax: +31(0)10 4089031 


\title{
An Econometric Analysis of ETF and ETF Futures in Financial and Energy Markets Using Generated Regressors*
}

\author{
Chia-Lin Chang \\ Department of Applied Economics \\ Department of Finance \\ National Chung Hsing University, Taiwan \\ Michael McAleer \\ Department of Quantitative Finance \\ National Tsing Hua University, Taiwan \\ and \\ Econometric Institute \\ Erasmus School of Economics \\ Erasmus University Rotterdam \\ and \\ Department of Quantitative Economics \\ Complutense University of Madrid, Spain \\ Chien-Hsun Wang \\ Institute of Statistics \\ National Tsing Hua University, Taiwan
}

Revised: June, 2016

\footnotetext{
* The authors are grateful to Wen-Ping Hsieh and Leh-Chyan So for helpful comments and suggestions. For financial support, the first author wishes to thank the National Science Council, Taiwan, and the third author acknowledges the Australian Research Council and the National Science Council, Taiwan.
} 


\begin{abstract}
It is well known that that there is an intrinsic link between the financial and energy sectors, which can be analyzed through their spillover effects, which are measures of how the shocks to returns in different assets affect each other's subsequent volatility in both spot and futures markets. Financial derivatives, which are not only highly representative of the underlying indices but can also be traded on both the spot and futures markets, include Exchange Traded Funds (ETFs), which is a tradable spot index whose aim is to replicate the return of an underlying benchmark index. When ETF futures are not available to examine spillover effects, "generated regressors" may be used to construct both Financial ETF futures and Energy ETF futures. The purpose of the paper is to investigate the co-volatility spillovers within and across the US energy and financial sectors in both spot and futures markets, by using "generated regressors" and a multivariate conditional volatility model, namely Diagonal BEKK. The daily data used are from $1998 / 12 / 23$ to $2016 / 4 / 22$. The data set is analyzed in its entirety, and also subdivided into three subset time periods. The empirical results show there is a significant relationship between the Financial ETF and Energy ETF in the spot and futures markets. Therefore, financial and energy ETFs are suitable for constructing a financial portfolio from an optimal risk management perspective, and also for dynamic hedging purposes.
\end{abstract}

Keywords: Exchange traded funds, financial and energy sectors, co-volatility spillovers, spot and futures prices, generated regressors, Diagonal BEKK.

JEL: C58, G13, G23, G31, Q41. 


\section{Introduction}

The Global Financial Crisis (GFC) was not only unexpected and unpredicted, but also had a marked and sustained impact on the world economy, in general, and also on international financial markets. After the GFC had subsided, oil prices recovered and stabilized at a price between US\$90 and US\$110 per barrel. This period of relative stability lasted from January 2011 to June 2014. However, in mid-2014 oil prices nosedived from a high of US\$107.95 per barrel to a low of US\$26.19 per barrel on February 11, 2016.

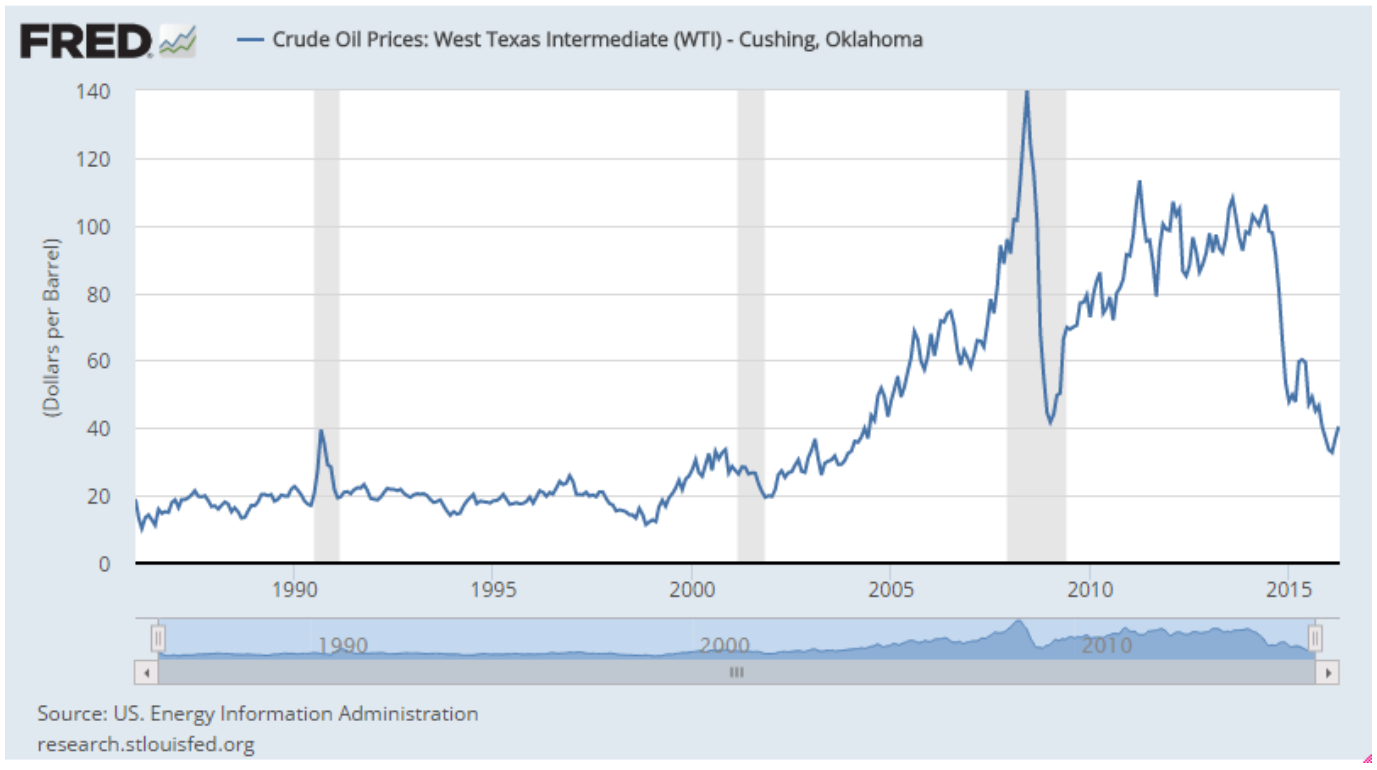

Figure 1: Crude Oil Prices: West Texas Intermediate (WTI) (1986-2016), Federal Reserve Economic Data.

According to a World Bank Report (Baffes, Kose, Ohnsorge, and Stocker, 2015), the plunge in oil prices was mainly driven by supply factors, namely the growth of unconventional oil production, such as Canadian oil sand and US shale oil. In particular, spurred by the shale oil boom, the USA nearly doubled its 2011 daily production levels to over 11 million barrels in 
June 2014. This surge allowed the USA to surpass Saudi Arabia as the oil and natural gas liquids global production leader, as reported by the International Energy Agency (IEA) (Bloomberg, July 4, 2014).

Responding to the surge in unconventional oil production, at the $166^{\text {th }}$ OPEC meeting held on November 27, 2014, OPEC decided not to curtail daily production, choosing instead to maintain a stable production of 30 million barrels per day, a policy that was enacted on December 14, 2011. This decision represented abandonment of OPEC's price targeting policy, with the tradeoff of possibly maintaining their current market share. However, this course of action may well have led to persistently low oil prices.

Such low oil prices have major ramifications on the banking sector. In addition to being forced to increase reserves for losses in the oil and gas portfolio, banks have also tried to shrink the credit lines offered to energy companies, even as energy companies become more dependent on banking loans. This sentiment is echoed by Devi Aurora, a senior director at Standard \& Poor's in New York, who was reported to have said (Financial Times, January 15, 2016): "[Energy] Companies have a tendency to draw on bank lines once other options dry up."

Faced with the dual pressures of low oil prices and a compromised ability to generate cash flows, oil companies are increasingly in danger of defaulting on loans. As reported in the Wall Street Journal, "Coming to the Oil Patch: Bad Loans to Outnumber the Good”, March 24, 2016:

"Fifty-one North American oil-and-gas producers have already filed for bankruptcy since the 
start of 2015, cases totaling $\$ 17.4$ billion in cumulative debt, according to law firm Haynes and Boone LLP. That trails the number from September 2008 to December 2009 during the global financial crisis, when there were 62 filings, but is expected to grow: About 175 companies are at high risk of not being able to meet loan covenants, according to Deloitte LLP."

From recent data, it is clear that oil price collapses of greater than $50 \%$ are not unprecedented events. For example, in 1986, there was a similar supply glut, which also led to a plunge in oil prices. In particular, that year marked OPEC's decision to revert its production target back to 30 million barrels per day, ending a significant decline in oil production since the Iran-Iraq war in 1979. This reversion, combined with an influx of oil supply from Mexico and the North Sea, caused the price of oil to collapse from US\$26.53 per barrel on January 6,1985 to US $\$ 10.25$ per barrel at its low point on March 31, 1986.

Around this time, the US government attempted to stimulate the sluggish economy and guard against deflation through several monetary and fiscal policies such as interest rate cuts. In spite of these measures, low oil prices persisted, thereby contributing to a global economic slowdown and a major downward correction in global financial markets on October 19, 1987. This day, which came to be known as Black Monday, saw the S\&P 500 drop 20.4\%, falling from 282.7 to 225.06 .

Another significant plunge in oil prices, this time of the order of $40 \%$, occurred between October 1997 and March 1998 amid the Asian Financial Crisis. This crisis was propelled primarily by an unexpected speculative attack on the Thai baht. The resulting drastic 
devaluation of the Thai currency not only wrought considerable damage to the East Asian economy, but also impacted global financial markets. The US Federal Reserve was forced to bail out a well-known hedge fund, Long Term Capital Management (LTCM), on September 23, 1998. During the economic slump, which lasted from 1997 to 1998, the global oil demand receded substantially, with oil prices reaching a low of US\$10.82 per barrel on December 10, 1998.

The most dramatic example of a sudden oil price collapse occurred a decade later in the wake of the Global Financial Crisis (GFC). While there is no consensus on the exact starting and ending dates of the GFC, for the purposes of this paper, we consider the GFC to span the time period from October 9, 2007 to March 9, 2009, which corresponds to the S\&P 500 dropping from a high of 1565.26 to a low of 672.88 . Oil prices reached an historical high of US\$145.31 per barrel on July 3, 2008, but tumbled to US\$30.28 per barrel just 6 months later, on December 23, 2009.

The GFC was spurred by a tsunami of financial chaos, including the housing bubble which, in turn, led to an epidemic of defaults in subprime mortgages. Subsequently, banks and insurance companies sold trillions of dollars of Credit Default Swaps (CDSs), which not only involved subprime mortgage loans, but also many other financial instruments and institutions. This resulted in Lehman Brothers going bankrupt on September 15, 2008, and the US Treasury being forced to bail out AIG in the same month. The GFC led to a dramatic diminution in the global oil demand and, in turn, tumbling energy prices (Van Vactor, January 1, 2009). 
In light of the preceding discussion, it is clear that there is an intrinsic link between the financial and energy sectors. One way to unearth the link between two or more sectors is by analyzing their spillover effects, which are measures of how the shocks to returns in different assets affect each other's subsequent volatility in both spot and futures markets.

In conducting spillover effect analysis, an important consideration is the choice of indices used to represent the assets or sectors under comparison. One reasonable selection of measures to examine volatility spillovers between the energy and financial sectors is the Energy Select Sector index (Ticker: IXE) and the Financial Select Sector index (Ticker: IXM). Both of these are sub-indices of S\&P500, reflecting the overall economic condition of their respective sectors. One shortcoming of using these indices, however, is the fact that they are not tradable, and hence may be of little practical use to investors.

One way to overcome this drawback is by employing derivatives of the IXE and IXM indices, as opposed to the indices themselves. Financial derivatives which are not only highly representative of the underlying indices but can also be traded on both the spot and futures markets, include Exchange Traded Funds (ETFs), otherwise known as implied tradable spot prices. Another financial derivative that has not yet been considered in practice, primarily as it typically does not exist in many financial markets, but may well have practical importance, is ETF futures.

For the reasons specified above, in order to probe the relationship between the energy and financial sectors, we apply not only IXE and IXM, but also ETFs and ETF futures in conducting 
spillover effect analysis within and across these two sectors. In particular, for both the energy and financial sectors, we will select one index (namely, IXE or IXM), one ETF, and construct one ETF futures from which to analyze all 15 possible pairwise combinations of spillover effects. The list of indices, ETFs, and ETF futures that we will use in the empirical analysis is as follows: Financial Select Sector Index (IXM), Energy Select Sector Index (IXE), Financial Select Sector SPDR Fund (XLF), Energy Select Sector SPDR Fund (XLE), Financial ETF futures (XLFf), and Energy ETF futures (XLEf).

An important point to clarify is that, despite the delisting of ETF futures in March 1, 2011, due to low trading volume, our analysis will include up-to-date ETF futures data from each sector. This is made possible by the use of "generated regressors" to construct both Financial ETF futures and Energy ETF futures. More details on this methodological approach will be discussed in Section 3.

An Exchange Traded Fund (ETF) is a tradable spot index whose aim is to replicate the return of an underlying benchmark index. For instance, SPDR ${ }^{\circledR}$ S\&P $500 \circledR$ ETF, issued by State Street Bank \& Trust Company, tracks the performance of the S\&P 500 Index. In contrast to investing in a single stock, ETFs invest in a basket of stocks or commodities, thereby diversifying the non-systematic risk and decreasing the levels of risk and volatility. Furthermore, unlike actively-managed mutual funds, most ETF managers take a passive management style and collect lower managing fees. Whereas mutual funds are limited to trades based on end-of-day prices, ETFs are traded like stocks. Besides the points listed above, ETFs have the following additional advantages over traditional mutual funds: 
(i) ETFs offer greater transparency compared with mutual funds in the sense that ETFs are required to reveal their holdings data on a daily basis, whereas mutual funds are mandated only to disclose holdings data on a quarterly basis.

(ii) ETFs are more flexible than mutual funds because investors can short sell them when they are bearish on the market. Although short selling may be considered risky compared with conventional investing, it can be a useful strategy if executed by savvy investors when the market is overvalued.

To recap, the purpose for this paper is to investigate spillover effects within and across the energy and financial sectors in terms of both the US spot and futures markets by applying indices, ETF, and ETF futures. For the empirical analysis, we select two indices and two ETFs, and generate two ETF futures from which to analyze all 15 possible pairwise combinations of spillover effects. Specifically, the list of variables we use is as follows: Financial Select Sector Index (IXM), Energy Select Sector Index (IXE), Financial Select Sector SPDR Fund (XLF), Energy Select Sector SPDR Fund (XLE), Financial ETF futures (XLFf), and Energy ETF futures (XLEf). In order to carry out this analysis, the techniques to be used are generated regressors and the multivariate conditional volatility Diagonal BEKK model. The empirical result will be discussed in greater detail in Section 5.

The remainder of the paper is organized as follows. In Section 2, the brief literature on the topic is reviewed. In Section 3, the empirical models are presented, and the data are discussed in Section 4. In Section 5, the empirical results are analyzed, and some concluding comments are given in Section 6. 


\section{Brief Literature Review}

The literature on the use of ETFs and testing for co-volatility spillovers is rather sparse. Chang, Li, and McAleer (2015) conducted a comprehensive review of the literature related to covolatility spillovers between energy markets and agricultural commodities. One of the major findings of their review paper was that most researchers fail to employ valid statistical techniques in testing for spillover effects. Multivariate conditional volatility models, namely BEKK and DCC, have typically been used to test for spillover effects between energy and agricultural markets. However, these models are either problematic in and of themselves (in the case of DCC), or have been used in erroneous manners (in the case of BEKK).

Specifically, the scalar DCC model lacks regularity conditions, while a serious technical deficiency related to estimating the full BEKK and scalar DCC models through QuasiMaximum Likelihood Estimates (QMLE) is the absence of any asymptotic properties. In contrast, the multivariate diagonal BEKK conditional volatility model possesses both regularity conditions and asymptotic properties. For these reasons, Chang, Wang, and McAleer (2016) applied the multivariate diagonal BEKK conditional volatility model in testing the volatility spillovers for bio-ethanol, sugarcane and corn, while this paper also applies the multivariate diagonal BEKK conditional volatility model in testing the volatility spillover effects within and across the US financial and energy markets. 
As described above, an exchange traded fund (ETF) is a tradable asset whose aim is to track an underlying index representing the economic condition of an entire sector. Thus, ETFs have great value to investors as they facilitate a systematic reduction in risk within a trading portfolio. Chang and Ke (2014) applied ETFs in the US energy sector to investigate the causality between flows and returns through the Vector-AutoRegressive (VAR) model to test four hypotheses, namely, the price pressure, information, feedback trading, and smoothing hypotheses. One noteworthy aspect of their methodology was the fact that they analyzed not just the entire sample period, but also divided the data into three sub-periods, namely, before, during, and after the Global Financial Crisis (GFC), a methodology also used by McAleer, Jimenez-Martin, and Perez-Amaral (2013). The use of the three sub-periods will also be used in the paper.

Chen and Huang (2010) used ETFs to examine volatility spillovers, albeit in a rudimentary manner, between an ETF and its underlying stock index in 9 different countries. They used the GARCH-ARMA and EGARCH-ARMA models, and found that there were volatility spillover effects for the stock index and ETF. Unfortunately, as in the case of estimating the full BEKK and scalar DCC models through Quasi-Maximum Likelihood Estimation (QMLE) methods, EGARCH has no known regularity conditions, and the statistical properties of the estimators of the parameters are not available under general conditions (see McAleer and Hafner, 2014).

One paper which used the diagonal BEKK model to examine ETFs was by Chang, Hsieh, and McAleer (2016). The authors investigated the causality and spillover effects between VIX, consisting of different moving average processes, and ETF returns by using vector 
autoregressive (VAR) models and diagonal BEKK models. The empirical results show that daily VIX returns have: (1) significant negative effects on European ETF returns in the short run; (2) stronger significant effects on single market ETF returns than on European ETF returns; and (3) lower impacts on the European ETF returns than on S\&P500 returns.

In some financial research contexts, it may be necessary or advantageous to generate a new index representing a certain sector that may be of interest. One way in which this may be performed is through the use of generated variables. Chang (2015) applied generated variables to develop a daily Tourism Financial Conditions Index (TFCI), based on nominal exchange rates, interest rates, and a tourism industry stock index that is listed on the Taiwan Stock Exchange. The empirical results indicated that the generated TFCI was accurately estimated through the estimated conditional means of the tourism stock index returns. As described in the introduction, the paper is interested in the co-volatility spillover effects across and within the financial and energy sectors in both the spot and futures markets. While energy and financial indices and ETFs are already available to analyze spot markets, it is necessary to use generated variables to construct ETF futures to analyze futures markets.

The paper combines several of the elements reviewed above to create a novel methodology to test for spillover effects in a statistically valid and comprehensive way that can be of immense practical use to investors. In particular, we use the diagonal BEKK model which, as mentioned above, has valid asymptotic and regularity properties as compared with the full BEKK and scalar DCC models, in order to test for spillovers within and across the financial spot (indices and ETFs) and futures (ETF futures via generated regressors) markets. This analysis is 
conducted for four time periods namely, before-GFC, during-GFC, after-GFC, and the entire sample period.

\section{Methodology}

The primary purpose of this paper is to test spillover effects among ETF and ETF futures in the financial and energy sectors. In the previous literature, a great deal of confusion has arisen about how spillover effects should be tested, with published academic papers often using dubious methodologies. Indeed, many so-called tests of spillovers are not, in fact, tests of spillovers at all. The following section presents three novel tests of spillovers, namely full volatility spillovers, full co-volatility spillovers, and partial co-volatility spillovers. For further details, see Chang, Li and McAleer (2015).

Tests of spillovers require estimation of a multivariate volatility model, with appropriate regularity conditions and asymptotic properties of the Quasi Maximum Likelihood Estimation (QMLE) of the associated parameters underlying the conditional mean and conditional variance. As the first step of the estimation of multivariate conditional volatility model is the estimation of multiple univariate conditional volatility models, an appropriate and widely-used univariate conditional volatility model will be discussed below.

This section is organized as follow:

(1) A brief discussion of the most widely-used univariate conditional volatility model;

(2) A definition of three novel spillover effects; 
(3) A discussion of the most widely-used multivariate model of conditional volatility.

In order to accommodate volatility spillover effects, alternative multivariate volatility models of the conditional covariances are available. Examples of such multivariate models include: (1) diagonal model of Bollerslev et al. (1988); (2) vech and diagonal vech models of Engle and Kroner (1995); (3) Baba, Engle, Kraft, and Kroner's (1985) (BEKK) multivariate GARCH model (see also Engle and Kroner (1995)); (4) constant conditional correlation (CCC) (specifically, multiple univariate rather than multivariate) GARCH model of Bollerslev (1990) (5) Ling and McAleer's (2003) vector ARMA-GARCH (VARMA-GARCH) model; (6) VARMA-asymmetric GARCH (VARMA- AGARCH) model of McAleer et al. (2009); (7) Engle's (2002) dynamic conditional correlation (technically, dynamic conditional covariance rather than correlation model) (DCC) model; and (8) Tse and Tsui's (2002) varying conditional correlation (VCC) model. For further details on most of these multivariate models see, for example, McAleer (2005).

The first step in estimating multivariate models is to obtain the standardized shocks from the conditional mean returns shocks. For this reason, the most widely used univariate conditional volatility model, namely GARCH, will be presented briefly, followed by the most widely estimated multivariate conditional covariance model, namely a specific version of BEKK.

Consider the conditional mean of financial returns as follows:

$$
y_{t}=E\left(y_{t} \mid I_{t-1}\right)+\varepsilon_{t}
$$


where the returns, $y_{t}=\Delta \log P_{t}$, represent the log-difference in financial commodity or agricultural prices, $P_{t}, I_{t-1}$ is the information set at time $t-1$, and $\varepsilon_{t}$ is a conditionally heteroskedastic returns shock. In order to derive conditional volatility specifications, it is necessary to specify the stochastic processes underlying the returns shocks, $\varepsilon_{t}$.

\subsection{Univariate Conditional Volatility Models}

Alternative univariate conditional volatility models are of interest in single index models to describe individual financial assets and markets. Univariate conditional volatilities can also be used to standardize the conditional covariances in alternative multivariate conditional volatility models to estimate conditional correlations, which are particularly useful in developing dynamic hedging strategies.

The most popular univariate conditional volatility model is discussed below, together with the associated regularity conditions, and the conditions underlying the asymptotic properties of consistency and asymptotic normality.

\subsubsection{Random Coefficient Autoregressive Process and GARCH}

Consider the random coefficient autoregressive process of order one:

$\varepsilon_{t}=\phi_{t} \varepsilon_{t-1}+\eta_{t}$ 
where

$\phi_{t} \sim \operatorname{iid}(0, \alpha)$,

$\eta_{t} \sim \operatorname{iid}(0, \omega)$

and $\eta_{t}=\varepsilon_{t} / \sqrt{h_{t}}$ is the standardized residual.

Tsay (1987) derived the ARCH(1) model of Engle (1982) from equation (2) as:

$h_{t}=E\left(\varepsilon_{t}^{2} \mid I_{t-1}\right)=\omega+\alpha \varepsilon_{t-1}^{2}$

where $h_{t}$ is conditional volatility, and $I_{t-1}$ is the information set available at time $t-1$. The use of an infinite lag length for the random coefficient autoregressive process in equation (2), with appropriate geometric restrictions (or stability conditions) on the random coefficients, leads to the GARCH model of Bollerslev (1986). From the specification of equation (2), it is clear that both $\omega$ and $\alpha$ should be positive as they are the unconditional variances of two separate stochastic processes.

The QMLE of the parameters of ARCH and GARCH have been shown to be consistent and asymptotically normal in several papers. For example, Ling and McAleer (2003) showed that the QMLE for $\operatorname{GARCH}(p, q)$ is consistent if the second moment is finite. Moreover, a weak sufficient log-moment condition for the QMLE of $\operatorname{GARCH}(1,1)$ to be consistent and asymptotically normal is given by: 
$E\left(\log \left(\alpha \eta_{t}^{2}+\beta\right)\right)<0, \quad|\beta|<1$

which is not easy to check in practice as it involves two unknown parameters and a random variable. The more restrictive second moment condition, namely $\alpha+\beta<1$, is much easier to check in practice.

In general, the proofs of the asymptotic properties follow from the fact that $\mathrm{ARCH}$ and $\mathrm{GARCH}$ can be derived from a random coefficient autoregressive process (see McAleer et al. (2008) for a general proof of multivariate models that are based on proving that they satisfy the regularity conditions given in Jeantheau (1998) for consistency).

\subsection{Multivariate Conditional Volatility Models}

The multivariate extension of univariate GARCH is given as variations of the BEKK model in Baba et al. (1985) and Engle and Kroner (1995).

In order to establish volatility spillovers in a multivariate framework, it is useful to define the multivariate extension of the relationship between the returns shocks and the standardized residuals, that is, $\eta_{t}=\varepsilon_{t} / \sqrt{h_{t}}$. The multivariate extension of equation (1), namely $y_{t}=$ $E\left(y_{t} \mid I_{t-1}\right)+\varepsilon_{t}$, can remain unchanged by assuming that the three components are now, respectively, $m \times 1$ vectors, where $m$ is the number of financial assets. 
The multivariate definition of the relationship between $\varepsilon_{t}$ and $\eta_{t}$ is:

$\varepsilon_{t}=D_{t}^{1 / 2} \eta_{t}$

where $D_{t}=\operatorname{diag}\left(h_{1 t}, h_{2 t}, \ldots, h_{m t}\right)$ is a diagonal matrix comprising the univariate conditional volatilities. Define the conditional covariance matrix of $\varepsilon_{t}$ as $Q_{t}$. As the $m \times 1$ vector, $\eta_{t}$, is assumed to be independently and identically distributed (iid) for all $m$ elements, the conditional correlation matrix of $\varepsilon_{t}$, which is equivalent to the conditional correlation matrix of $\eta_{t}$, is given by $\Gamma_{t}$. Therefore, the conditional expectation of (4) is defined as:

$Q_{t}=D_{t}^{1 / 2} \Gamma_{t} D_{t}^{1 / 2}$

Equivalently, the conditional correlation matrix, $\Gamma_{t}$, can be defined as:

$\Gamma_{t}=D_{t}^{-1 / 2} Q_{t} D_{t}^{-1 / 2}$

Equation (5) is useful if a model of $\Gamma_{t}$ is available for purposes of estimating $Q_{t}$, whereas equation (6) is useful if a model of $Q_{t}$ is available for purposes of estimating $\Gamma_{t}$.

Equation (5) is convenient for a discussion of volatility spillover effects, while both equations (5) and (6) are instructive for a discussion of asymptotic properties. As the elements of $D_{t}$ are consistent and asymptotically normal, the consistency of $Q_{t}$ in (5) depends on consistent estimation of $\Gamma_{t}$, whereas the consistency of $\Gamma_{t}$ in (6) depends on consistent estimation of 
$Q_{t}$. As both $Q_{t}$ and $\Gamma_{t}$ are products of matrices, neither the QMLE of $Q_{t}$ nor $\Gamma_{t}$ can be asymptotically normal, based on the definitions given in equations (5) and (6).

\subsection{Full and Partial Volatility and Co-volatility Spillovers}

Volatility spillovers are defined in Chang, Li and McAleer (2015) as the delayed effect of a returns shock in one asset on the subsequent volatility or co-volatility in another asset. Therefore, a model relating $Q_{t}$ to returns shocks is essential, and this will be addressed in the following sub-section. Spillovers can be defined in terms of full volatility spillovers and full co-volatility spillovers, as well as partial co-volatility spillovers, as follows:

(1) Full volatility spillovers: $\partial Q_{i i t} / \partial \varepsilon_{k t-1}, k \neq i$

(2) Full co-volatility spillovers: $\partial Q_{i j t} / \partial \varepsilon_{k t-1}, i \neq j, k \neq i, j$

(3) Partial co-volatility spillovers: $\partial Q_{i j t} / \partial \varepsilon_{k t-1}, i \neq j, k=$ either $i$ or $j$

where $i, j, k=1 \ldots m ; \varepsilon_{t}$ is returns shocks, and $Q_{t}$ is the conditional covariance matrix of $\varepsilon_{t}$. Volatility spillovers in the spot and derivatives markets is crucial for purposes of dynamic hedging.

Full volatility spillovers occur when the returns shock from financial asset $k$ affects the volatility of a different financial asset $i$. 
Full co-volatility spillovers occur when the returns shock from financial asset $k$ affects the co-volatility between two different financial assets, $i$ and $j$.

Partial co-volatility spillovers occur when the returns shock from financial asset $k$ affects the co-volatility between two financial assets, $i$ and $j$, one of which can be asset $k$.

When $m=2$, only (1) and (3) are possible as full co-volatility spillovers depend on the existence of a third financial asset.

As mentioned above, spillovers require a model that relates the conditional volatility matrix, $Q_{t}$, to a matrix of delayed returns shocks. The most frequently used models of multivariate conditional covariance are alternative specifications of the BEKK model, with appropriate parametric restrictions, which will be considered below.

\subsection{Diagonal and Scalar BEKK}

The vector random coefficient autoregressive process of order one is the multivariate extension of equation (2), and is given as:

$\varepsilon_{t}=\Phi_{t} \varepsilon_{t-1}+\eta_{t}$

where $\varepsilon_{t}$ and $\eta_{t}$ are $m \times 1$ vectors, $\Phi_{t}$ is an $m \times m$ matrix of random coefficients, and:

$\Phi_{t} \sim \operatorname{iid}(0, A)$, 
$\eta_{t} \sim \operatorname{iid}\left(0, Q Q^{\prime}\right)$

Technically, a vectorization of a full (that is, non-diagonal or non-scalar) matrix A to vec A can have dimension as high as $m^{2} \times m^{2}$, whereas vectorization of a symmetric matrix A to vech A can have dimension as low as $m(m-1) / 2 \times m(m-1) / 2$.

In a case where $\mathrm{A}$ is either a diagonal matrix or the special case of a scalar matrix, $A=a I_{m}$, McAleer et al. (2008) showed that the multivariate extension of $\operatorname{GARCH}(1,1)$ from equation (10), incorporating an infinite geometric lag in terms of the returns shocks, is given as the diagonal or scalar BEKK model, namely:

$Q_{t}=Q Q^{\prime}+A \varepsilon_{t-1} \varepsilon_{t-1}^{\prime} A^{\prime}+B Q_{t-1} B^{\prime}$

where $A$ and $B$ are both either diagonal or scalar matrices. The matrix $A$ is crucial in the interpretation of symmetric and asymmetric weights attached to the returns shocks, as well as the subsequent analysis of spillover effects.

McAleer et al. (2008) showed that the QMLE of the parameters of the diagonal or scalar BEKK models were consistent and asymptotically normal, so that standard statistical inference on testing hypotheses is valid. Moreover, as $Q_{t}$ in (11) can be estimated consistently, $\Gamma_{t}$ in equation (6) can also be estimated consistently. 
In terms of volatility spillovers, as the off-diagonal terms in the second term on the right-hand side of equation (11), $\varepsilon_{t-1} \varepsilon_{t-1}^{\prime} A^{\prime}$, have typical $(i, j)$ elements $a_{i i} a_{j j} \varepsilon_{i t-1} \varepsilon_{j t-1}, i \neq j, i, j=$ $1, \ldots, m$, there are no full volatility or full co-volatility spillovers. However, partial co-volatility spillovers are not only possible, but they can also be tested using valid statistical procedures.

\subsection{Triangular, Hadamard and full BEKK}

Without actually deriving the model from an appropriate stochastic process, Baba et al. (1985) and Engle and Kroner (1995) considered the full BEKK model, as well as the special cases of triangular and Hadamard (element-by-element multiplication) BEKK models. The specification of the multivariate model is the same as the specification in equation (11), namely:

$Q_{t}=Q Q^{\prime}+A \varepsilon_{t-1} \varepsilon_{t-1}^{\prime} A^{\prime}+B Q_{t-1} B^{\prime}$

except that $A$ and $B$ are full, Hadamard or triangular matrices, rather than diagonal or scalar matrices, as in (11).

Although it is possible to examine spillover effects using each of these models, it is not possible to test or analyze spillover effects as the QMLE of the parameters in equation (12) have no known asymptotic properties. 
Although estimation of the full, Hadamard and triangular BEKK models is available in some standard econometric and statistical software packages, it is not clear how the likelihood functions might be determined. Moreover, the so-called "curse of dimensionality", whereby the number of parameters to be estimated is excessively large, makes convergence of any estimation algorithm somewhat problematic.

This is in sharp contrast to a number of published papers in the literature, whereby volatility spillovers have been tested incorrectly based on the off-diagonal terms in the matrix $A$ in equation (12).

\subsection{Generated Regressors}

One of the primary purposes of the paper is to investigate the spillover effects within and across the energy and financial sectors for both US spot and futures market by applying indices, ETF, and ETF futures. While energy and financial indices and ETFs are already available for spot markets, it is necessary to use generated variables to construct ETF futures for futures markets. The generated ETF futures proposed in the paper focus on economic activities related to the financial and energy industries, respectively. The three components of the Financial ETF futures (XLFf), each of which can be constructed from data downloaded from Bloomberg or Yahoo Finance, are as follows:

(1) Financial Select Sector SPDR Fund (XLF);

(2) Generic $1^{\text {st }}$ S\&P 500 index futures (SP1); and 
(3) Generic $1^{\text {st }}$ FTSE 100 index futures (Z1).

The other three components of the Energy ETF futures (XLEf), each of which can be constructed from data downloaded from Bloomberg or Yahoo Finance, are as follows:

\section{(1) Energy Select Sector SPDR Fund (XLE); \\ (2) Generic $1^{\text {st }}$ Crude Oil WTI futures (CL1); and \\ (3) Generic $1^{\text {st }}$ Natural Gas futures (NG1).}

The ETF futures discussed above are based on estimation of a regression model, which may be referred to as the generating model. The model-based weights for the components of Financial ETF futures and Energy ETF futures will be estimated by OLS. The traditional method of examining the statistical properties of generated variables, and more specifically generated regressors, use variables that are typically stationary. In empirical finance, the variables considered can be financial returns, in which the variables are typically stationary, or financial stock prices, where the variables are typically non-stationary.

The specific model that is used to generate ETF futures is based on financial price variables, all of which are non-stationary. Consequently, there would seem to be no known optimality properties for the OLS estimates of ETF futures. For this reason, the generated variable is interpreted solely as an estimate of ETF, with no optimal statistical properties claimed for the estimated parameters in the generating model. In comparison, where the variables are 
stationary, Ordinary Least Squares (OLS) can be shown to be efficient (see, for example, McAleer and McKenzie (1991), McAleer (1992), and Fiebig, McAleer and Bartels (1992)).

The models to be estimated below are linear in the variables, with the appropriate weights to be estimated empirically. Accordingly, XLFf is defined as:

$\mathrm{XLFF}_{t}=\mathrm{c}+\theta_{1} \mathrm{XLF}_{t-1}+\theta_{2} \mathrm{SP} 1_{t-1}+\theta_{3} \mathrm{Z1}_{t-1}+u_{t}, u_{t} \sim D\left(0, \sigma_{u}^{2}\right)$

where $\mathrm{c}$ denotes the constant term, and $u_{t}$ denotes the shocks to XLFf, which need not be independently or identically distributed, especially for daily data. The parameters $\theta_{1}, \theta_{2}$ and $\theta_{3}$ are the weights attached to one-period lagged Financial ETF, Generic $1^{\text {st }}$ S\&P 500 index futures, and Generic FTSE 100 index futures, respectively.

As XLFf is a latent variable, it is necessary to link XLFf to observable data. The latent variable is defined as being the conditional mean of an observable variable, namely the Financial Select Sector SPDR Fund (XLF), which is a tradable spot index, reflecting the financial select index that is listed on the NYSE, as follows:

$\mathrm{XLF}_{t}=\mathrm{XLFF}_{t}+v_{t}, v_{t} \sim D\left(0, \sigma_{v}^{2}\right)$

where XLF is observed, XLFf is latent, and the measurement error in XLF is denoted by $v_{t}$, which need not be independently or identically distributed, especially for daily data. 
Given the zero mean assumption for $v_{t}$, the means of XLF and XLFf will be identical, as will their estimates. Using equations (13) and (14), the empirical model for estimating the weights for XLF is given as:

$\mathrm{XLF}_{t}=\mathrm{c}+\theta_{1} \mathrm{XLF}_{t-1}+\theta_{2} \mathrm{SP} 1_{t-1}+\theta_{3} \mathrm{Z}_{t-1}+\varepsilon_{t}, \varepsilon_{t}=u_{t}+v_{t} \sim D\left(0, \sigma_{\varepsilon}^{2}\right)$

where $\varepsilon_{t}=u_{t}+v_{t}$, which should be distinguished from the return shocks, $\varepsilon_{t}$, in equations (1) and (4) above, need not be independently or identically distributed, especially for daily data.

The parameters in equation (15) can be estimated by OLS or QMLE, depending on the specification of the conditional volatility of $\varepsilon_{t}$, to yield estimates of XLF, if SP1 and Z1 are stationary. As XLF is a non-stationary price, there is no reason to expect the combined error, $\varepsilon_{t}$, to be conditionally heteroskedastic. Alternatively, Instrumental Variables (IV) or Generalized Method of Moments (GMM) can be used to estimate the parameters in equation (15) to obtain an estimate of XLF, and hence also an estimate of the latent variable, XLFf, although finding suitable instruments can be problematic when daily data are used.

Cointegration could also be used to estimate the parameters in equation (15), but only if consistent estimates of the parameters are desired, and if statistical inference is intended for the estimates. As we are interested only in the fitted values of ETF to generate ETF futures, namely XLF to obtain XLFf, these alternative methods are eschewed in favour of the Ordinary Least 
Squares (OLS) estimates. In view of the definition in equation (14), the estimates of XLF will also provide estimates of the latent XLFf.

Similar logic to the above applies to the energy case. XLEf is defined as follows:

$\mathrm{XLE}_{t}=\mathrm{XLEF}_{t}+v_{t}, v_{t} \sim D\left(0, \sigma_{v}^{2}\right)$

where XLE is observed, XLEf is latent, and the measurement error in XLE is denoted by $v_{t}$, which need not be independently or identically distributed, especially for daily data.

Given the zero mean assumption for $v_{t}$, the means of XLE and XLEf will be identical, as will their estimates. Using equations (13) and (14), the empirical model for estimating the weights for XLE is given as:

$\mathrm{XLE}_{t}=\mathrm{c}+\theta_{1} \mathrm{XLE}_{t-1}+\theta_{2} \mathrm{CL1}_{t-1}+\theta_{3} \mathrm{NG1}_{t-1}+\varepsilon_{t}, \varepsilon_{t}=u_{t}+v_{t} \sim D\left(0, \sigma_{\varepsilon}{ }^{2}\right)$

where $\varepsilon_{t}=u_{t}+v_{t}$ need not be independently or identically distributed, especially for daily data.

As there would seem to be no known optimality properties for the OLS estimates of ETF futures, the OLS estimates of XLE will be used to estimate XLEf, though no optimality properties are claimed for the generated XLE futures. 


\section{Data and Variables}

As shown in Table 1, we choose the following indices, ETFs, and ETF futures for the empirical analysis: Financial Select Sector Index (IXM), Energy Select Sector Index (IXE), Financial Select Sector SPDR Fund (XLF), Energy Select Sector SPDR Fund (XLE), Financial ETF futures (XLFf), and Energy ETF futures (XLEf).

\section{[Insert Table 1 here]}

The Financial Select Sector index (Ticker: IXM), launched on December 16, 1998, is a subindex of S\&P500 comprising 92 financial-related S\&P 500 stocks. The classification is based on the Global Industry Classification Standard (GICS $\left.{ }^{\circledR}\right)$. The index represents the performance of the US financial industry. Components of the Financial Select Sector are weighted by their float-adjusted market capitalization, and the Select Sector Indices are rebalanced quarterly. The three largest constituents of the financial sector are Berkshire Hathaway B, Wells Fargo \& Co, and JP Morgan Chase \& Co. The related ETF tracking IXM is the Financial Select Sector SPDR Fund (Ticker: XLF), as listed on the New York Stock Exchange.

Correspondingly, the Energy Select Sector index (Ticker: IXE), launched on December 16, 1998 , is a sub-index of S\&P500 comprised of 38 energy-related stocks of the S\&P 500. The classification is based on the Global Industry Classification Standard (GICS $®$ ). This index represents the performance of the US energy industry. Components of the Energy Select Sector 
are weighted by their float-adjusted market capitalization, and the Select Sector Indices are rebalanced quarterly. The related ETFs tracking IXE is the Energy Select Sector SPDR Fund (Ticker: XLE), as listed on the New York Stock Exchange.

The Financial Select Sector SPDR ${ }^{\circ}$ Fund (Ticker: XLF), issued by SSGA Funds Management, Inc. and listed on the New York Stock Exchange since December 16, 1998, is the most representative financial ETF, with the largest total assets and average trading volume in the financial sector. This ETF seeks to replicate the performance of the Financial Select Sector Index. As of May 31, 2016, the industry allocation of XLF consisted of Banks (34.47\%), Real Estate Investment Trusts (REITs) $(18.30 \%)$, Insurance (16.83\%), Diversified Financial Services (13.04\%), Capital Markets (12.01\%), Consumer Finance (4.92\%), Real Estate Management \& Development (0.29\%), and Unassigned (0.10\%). The top 3 holdings of XLF are Berkshire Hathaway Inc. Class B (8.84\%), JPMorgan Chase \& Co. (8.04\%), and Wells Fargo \& Company $(7.87 \%)$,

Correspondingly, the Energy Select Sector SPDR ${ }^{\circledR}$ Fund (Ticker: XLE), issued by SSGA Funds Management, Inc. and listed on the New York Stock Exchange since December 16, 1998, is the most representative energy ETF, with the largest total assets and average trading volume in the energy sector. This ETF seeks to replicate the performance of the Energy Select Sector Index. As of May 31, 2016, the industry allocation of XLE consisted of Oil Gas \& Consumable Fuels (83.19\%), Energy Equipment \& Services (16.66\%), and Unassigned (0.15\%). The top 3 holdings of XLE are Exxon Mobil Corporation (18.85\%), Chevron Corporation (14.68\%), and Schlumberger NV (8.37\%). 
The financial ETF futures (XLFf) was generated from the Financial Select Sector SPDR ${ }^{\circledR}$ Fund (XLF), generic $1^{\text {st }}$ S\&P 500 index futures (Bloomberg ticker: SP1), and generic $1^{\text {st }}$ FTSE 100 index futures (Bloomberg ticker: Z1). The generic $1^{\text {st }} \mathrm{S} \& \mathrm{P} 500$ index futures is the continuous contract constructed by the front-month futures contract of S\&P 500 index futures (Ticker: SPX), the latter having been introduced by the Chicago Mercantile Exchange (CME) in 1982. Meanwhile, the generic $1^{\text {st }}$ FTSE 100 index futures is the continuous contract constructed by front-month futures contract of FTSE 100 index futures, the latter having been launched by the London International Financial Futures and Options Exchange (LIFFE) in 1984.

Estimation of XLFf using Generated Regressors via the software R is shown in equation (18).

$$
\begin{aligned}
& \mathrm{XLFf}_{t}=0.0642+0.998 \mathrm{XLF}_{t-1}+0.000022 \mathrm{SP} 1_{t-1}-0.0000097 \mathrm{Z} 1_{t-1} \\
& (1.858) \quad(956.103) \quad(0.797) \quad(-0.978) \\
& \bar{R}^{2}=0.996
\end{aligned}
$$

where XLFf is Financial ETF futures, XLF is Financial Select Sector SPDR ${ }^{\circledR}$ Fund, SP1 is Generic $1^{\text {st }}$ S\&P 500 index futures, Z1 is generic $1^{\text {st }}$ FTSE 100 index futures, and t-ratios are shown in parentheses. As stated previously, the t-ratios do not have the standard asymptotic normal distribution as the variables are non-stationary.

The energy ETF futures (XLEf) are generated from the Energy Select Sector SPDR ${ }^{\circ}$ Fund (XLE), Crude Oil futures (CL1), and Natural Gas futures (NG1). The generic $1^{\text {st }}$ Crude Oil 
futures is the continuous contract constructed by the front-month futures contract of Crude Oil WTI futures (Ticker: CL), listed in the New York Mercantile Exchange (NYMEX). The generic $1^{\text {st }}$ Natural Gas futures is the continuous contract constructed by the front-month futures contract of Natural Gas futures (Ticker: NG) listed in the New York Mercantile Exchange (NYMEX).

Estimation of XLEf using Generated Regressors via the software R is given in equation (19).

$$
\begin{aligned}
& \mathrm{XLEf}_{t}=0.0632+0.9989 \mathrm{XLE}_{t-1}+0.00024 \mathrm{CL} 1_{t-1}-0.00325 \mathrm{NG} 1_{t-1} \\
& \begin{array}{llll}
(1.606) & (875.35) & (0.271) & (-0.543)
\end{array} \\
& \bar{R}^{2}=0.9986
\end{aligned}
$$

where XLEf is Energy ETF futures, XLE is Energy Select Sector SPDR ${ }^{\circ}$ Fund, CL1 is Generic $1^{\text {st }}$ Crude Oil WTI futures, NG1 is Generic $1^{\text {st }}$ Natural Gas futures, and t-ratios are shown in parentheses. As stated previously, the t-ratios do not have the standard asymptotic normal distribution as the variables are non-stationary.

Daily data for the financial select sector index, energy select sector index, financial ETF, energy ETF, and the constituents of the Financial ETF futures and Energy ETF futures (namely, generic $1^{\text {st }}$ S\&P 500 index futures, generic $1^{\text {st }}$ FTSE 500 index futures, generic $1^{\text {st }}$ Crude Oil futures, and generic $1^{\text {st }}$ Natural Gas futures), were downloaded from Bloomberg or Yahoo Finance. In the case of a national holiday, the missing value is replaced by the value of the previous day. ETF fund returns are calculated by taking the log difference of adjusted prices 
and multiplying by 100 , that is, $\left(\log P_{t}-\log P_{t-1}\right) * 100$. The relevant descriptive statistics are shown in Table 2, implying that the returns of all variables are not normal. The Augmented Dickey Fuller (ADF) and PP (Phillips-Perron) test for unit roots are shown in Table 3. The unit roots tests indicate that the returns of all variables are stationary.

\section{[Insert Tables 2 and 3 here]}

The empirical analysis was conducted in its entirety and also subdivided into three sub-periods, namely (i) before-GFC, from December 22, 1998 to October 8, 2007; (ii) during-GFC, from October 9, 2007 to March 9, 2009; (iii) after-GFC, from March 10, 2009 to April 22, 2016; (iv) all (full sample), from December 22, 1998 to April 22, 2016. The numbers of observations for each period are 2292, 370, 1859, and 4521, respectively.

\section{Empirical Results for Co-volatility Spillovers}

\subsection{Hypothesis Testing of Co-volatility Spillovers}

This paper uses the Diagonal BEKK model, in which the co-volatility spillover effects are a function of the diagonal elements of matrix $A$ and the returns shocks of asset $i$ at time $t-1$. A rejection of the null hypothesis $\mathrm{H}_{0}$, as shown in the definition of the test of co-volatility spillover effects in Section 3, indicates significance of the co-volatility spillovers from the returns shocks of asset $j$ at time $t-1$ to the co-volatility between assets $i$ and $j$ at time $t$. 
In the empirical analysis, we selected two indices and two ETFs, and generated two ETF futures, from which to analyze all 15 possible pairwise combinations of spillover effects based on the multivariate diagonal BEKK model, specifically, the co-volatility spillovers for all cases in which the estimates of $A$ in the Diagonal BEKK model are significant. The diagonal BEKK model shown in equation (11) was estimated by QMLE using the econometric software package EViews 8.

The list of variables used is as follows: Financial Select Sector Index (IXM), Energy Select Sector Index (IXE), Financial Select Sector SPDR Fund (XLF), Energy Select Sector SPDR Fund (XLE), Financial ETF futures (XLFf), and Energy ETF futures (XLEf).

\subsection{Calculating Average Co-volatility Spillovers}

Table 4 shows the estimates of the diagonal elements of $A$ in the Diagonal BEKK model for each pairwise comparison analyzed (as described below), while Table 5 shows the mean returns shocks for each asset, both for the entire time period and for each of the three sub-periods. Tables 6 shows the mean co-volatility spillovers, which are calculated by applying the definition of the co-volatility spillover effects discussed in Section 3.

\section{[Insert Tables 4 - 6 here]}

As can be seen in Table 6 and the explanation below, the data were separated into 5 groups, which will be described in detail below. 
Group 1: Cross-sector spot-spot spillover effects, specifically, the spillover effects between each of the pairs: (a) financial index and energy index, (b) financial ETF and energy ETF, (c) financial index and energy ETF, and (d) energy index and financial ETF.

Group 2: Cross-sector futures-futures spillover effects, specifically, the spillover effects between (a) financial ETF futures and energy ETF futures.

Group 3: Cross-sector spot-futures spillover effects, specifically, the spillover effects between each of the pairs: (a) financial index and energy ETF futures, (b) financial ETF and energy ETF futures, (c) energy index and financial ETF futures, and (d) energy ETF and financial ETF futures.

Group 4: Within-sector spot-spot spillover effects, specifically, the spillover effects between (a) financial index and financial ETF and (b) energy index and energy ETF.

Group 5: Within-sector spot-futures spillover effects, specifically, the spillover effects between each of the pairs: (a) financial index and financial ETF futures, (b) financial ETF and financial ETF futures, (c) energy index and energy ETF futures, and (d) energy ETF and energy ETF futures.

The following paragraphs describe the average co-volatility spillover effects for each of the 5 groups mentioned above, and also across each of the 4 time periods, namely "before- GFC", 
"during-GFC", "after-GFC", and "all".

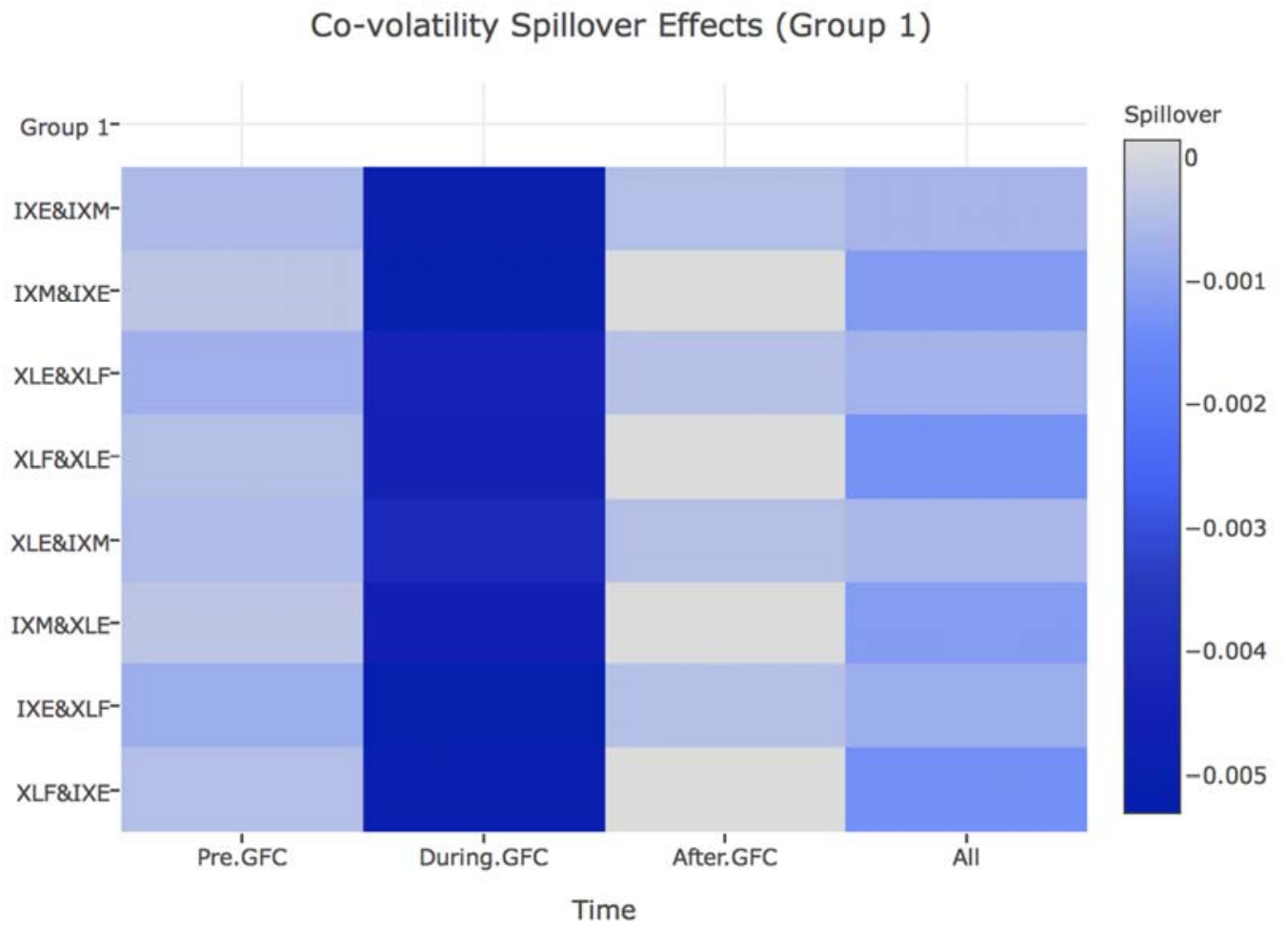

In Group 1, before-GFC, namely, cross-sector spot-spot spillovers, it was found that in all cases, co-volatility spillovers were statistically significant and negative. For each of the four pairs, the magnitude of the spillovers of the financial spot asset, namely, IXM (Financial Select Sector Index) or XLF (Financial ETF), on subsequent co-volatility between itself and its corresponding energy spot asset, namely IXE (Energy Select Sector Index) or XLE (energy ETF), was numerically greater than the spillovers of the energy spot asset on the same subsequent co-volatility pair. 
In Group 1, during-GFC, it was found that in all cases, co-volatility spillovers were again statistically significant and negative. For each pair, the magnitude of the spillovers of the financial spot asset, namely, IXM (Financial Select Sector Index) or XLF (Financial ETF), on subsequent co-volatility between itself and its corresponding energy spot asset, namely, IXE (Energy Select Sector Index) or XLE (energy ETF), was similar to as the spillover effect of the energy spot asset on the same subsequent co-volatility pair.

In Group 1, after-GFC, it was found that in all cases, co-volatility spillovers were statistically significant. For each pair, the spillovers of the financial spot asset, namely, IXM (Financial Select Sector Index) or XLF (Financial ETF) on subsequent co-volatility between itself and its corresponding energy spot asset, namely, IXE (Energy Select Sector Index) or XLE (energy ETF), was negative and greater than the positive spillovers of the energy spot asset on the same subsequent co-volatility pair.

In terms of the aggregation of the three periods for Group 1, it was found that in all cases, co-volatility spillovers were statistically significant and negative. For each pair, the magnitude of the spillovers of the financial spot asset, namely, IXM (Financial Select Sector Index) or XLF (Financial ETF) on subsequent co-volatility between itself and its corresponding energy spot asset, namely, IXE (Energy Select Sector Index) or XLE (energy ETF), was less than the spillovers of the energy spot asset on the same subsequent co-volatility pair. 


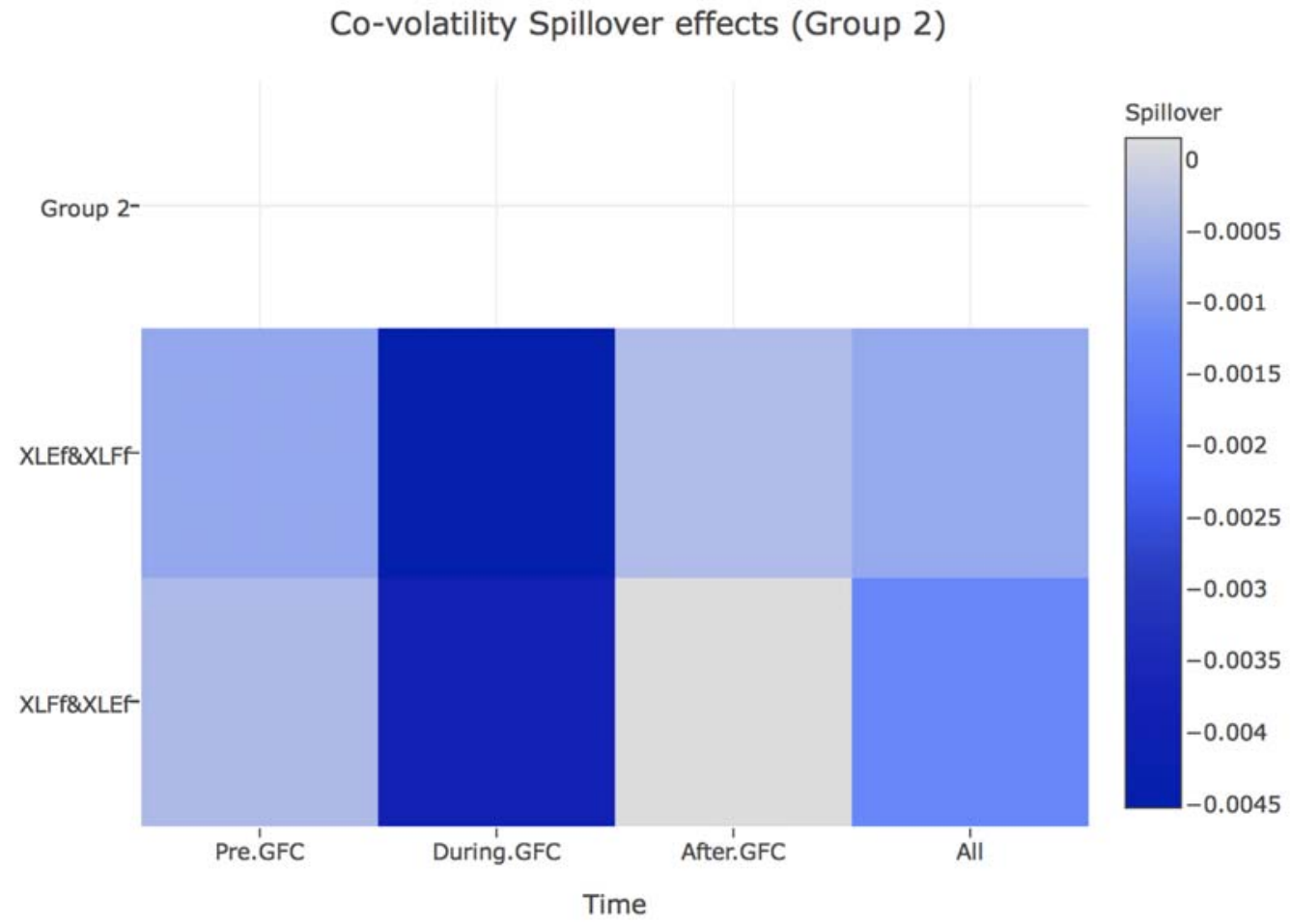

In Group 2, namely, cross-sector futures-futures spillover effects, it was found that for all three sub-periods, co-volatility spillovers were statistically significant. For the lone pair in this group, the magnitude of the spillovers of the financial futures asset, namely, XLFf (Financial ETF futures) on subsequent co-volatility between itself and its corresponding energy ETF futures, namely, XLEf (energy ETF futures), was greater than the spillovers of the energy ETF futures on the same subsequent co-volatility pair. However, when the three sub-periods were combined, the opposite pattern was revealed. In particular, the spillovers of the financial futures asset, namely, XLFf (Financial ETF futures) on subsequent co-volatility between itself and the energy ETF futures, namely, XLEf (energy ETF futures), was less than the spillovers of the energy ETF futures on the same subsequent co-volatility pair. 


\section{Co-volatility Spillover effects (Group 3)}

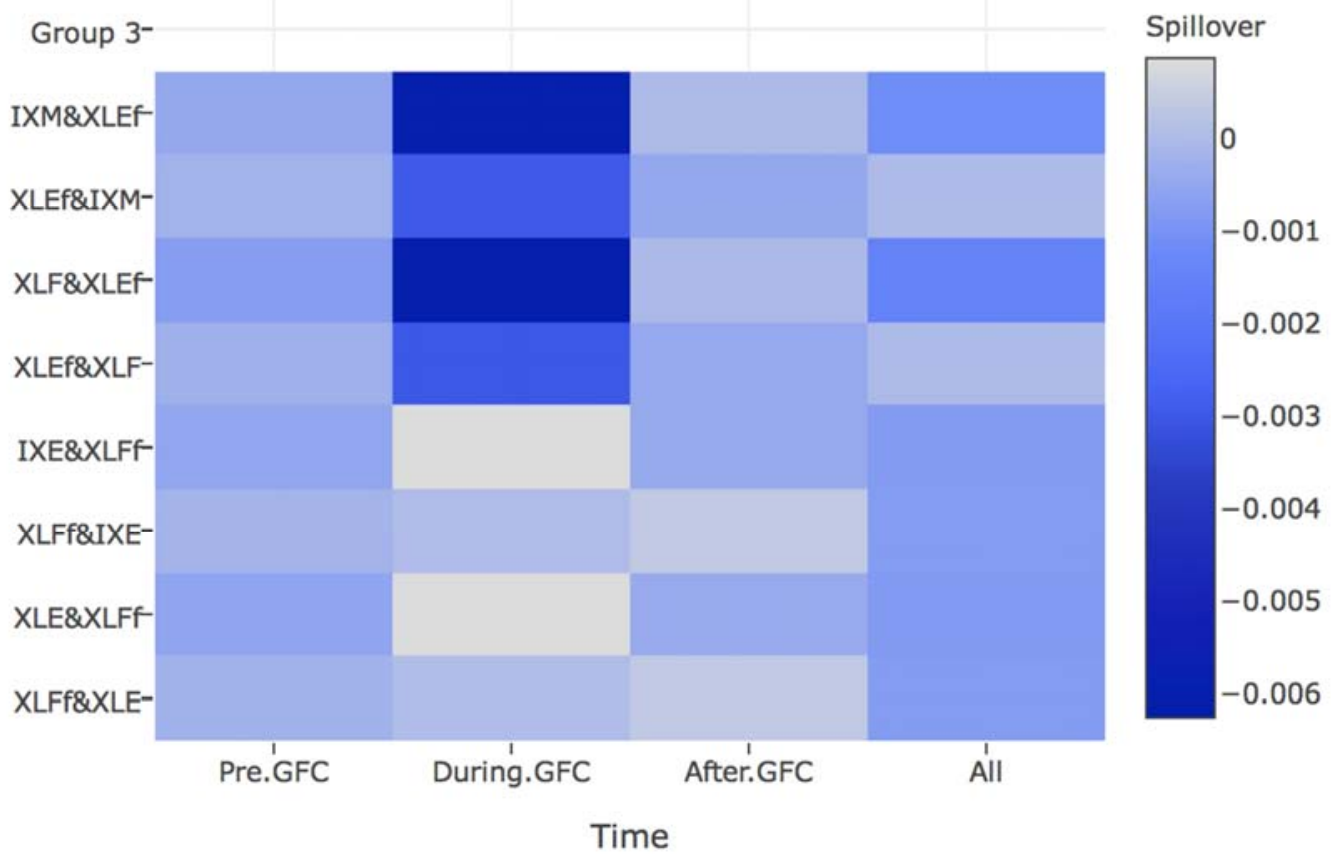

In Group 3, before-GFC, namely, cross-sector spot-futures spillovers, it was found that in all cases, co-volatility spillovers were statistically significant and negative. For each pair, the magnitude of the spillover of the futures asset, namely, XLFf (Financial ETF futures) or XLEf (Energy ETF futures), on subsequent co-volatility between itself and its corresponding crosssector spot asset, namely, IXE (Energy Select Sector Index) or XLE (energy ETF) and IXM (Financial Select Sector Index) or XLF (financial ETF), respectively, was greater than the spillovers of the spot asset on the same subsequent co-volatility pair.

In Group 3, during-GFC, it was found that co-volatility spillovers between XLEf (energy ETF futures) and XLF (financial ETF) or IXM (financial index), namely, cases 3.a.1 to 3.b.2, were statistically significant and negative. For each pair, the magnitude of spillovers of XLEf (Energy ETF futures) on subsequent co-volatility between itself and its corresponding cross- 
sector spot asset, namely, IXM (Financial Select Sector Index) or XLF (financial ETF), was greater than the spillovers of the spot asset on the same subsequent co-volatility pair. However, in each of the cases involving the co-volatility between financial ETF futures and a spot energy asset (namely, energy ETF or energy index), specifically, cases 3.c.1 to 3.d.2, non-significant co-volatility effects were found.

In Group 3, after-GFC, it was found that in all cases, co-volatility spillovers were statistically significant. For each pair, the magnitude of the spillover effect of XLFf (Financial ETF futures) on subsequent co-volatility between itself and its corresponding cross-sector energy spot asset, namely, IXE (Energy Select Sector Index) or XLE (energy ETF), was greater than the spillovers of the energy spot asset on the same subsequent co-volatility pair. However, the spillovers of XLEf (energy ETF futures) on subsequent co-volatility between itself and its corresponding cross-sector financial spot asset, namely, IXM (financial Select Sector Index) or XLF (financial ETF), were positive and smaller than the negative spillovers of the financial spot asset on the same subsequent co-volatility pair.

In Group 3, combining all three periods, it was found that in all cases, co-volatility spillovers were statistically significant and negative. For each pair, the magnitude of spillovers of XLFf (Financial ETF futures) on subsequent co-volatility between itself and its corresponding crosssector energy spot asset, namely, IXE (Energy Select Sector Index) or XLE (energy ETF), was the similar to the spillovers of the energy spot asset on the same subsequent co-volatility pair. However, the spillovers of XLEf (energy ETF futures) on subsequent co-volatility between itself and its corresponding cross-sector financial spot asset, namely, IXM (financial Select 
Sector Index) or XLF (financial ETF), were greater than the spillovers of the financial spot asset on the same subsequent co-volatility pair.

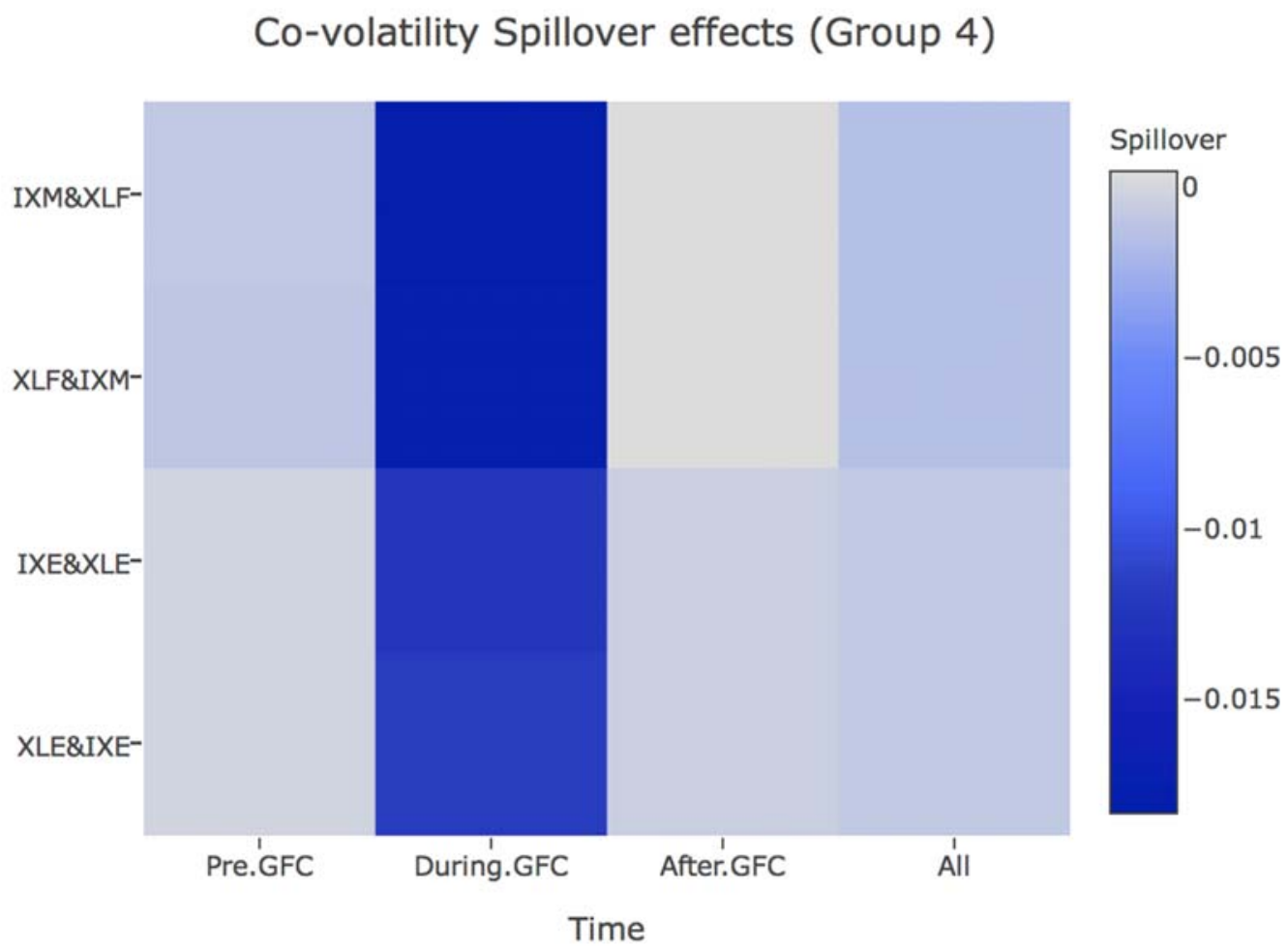

In Group 4, it was found that in all cases, co-volatility spillovers were statistically significant over the four time periods. In terms of the magnitude of within-sector spot-spot co-volatility effects, the spillovers of IXM (Financial Select Sector Index) on subsequent co-volatility between itself and XLF (Financial ETF), was the similar to the spillovers of XLF on the same subsequent co-volatility pair, namely, cases 4.a.1 and 4.a.2. This symmetry was also found for the pair involving co-volatility spillovers between the XLE (energy ETF) and IXE (energy index), namely, cases 4.b.1 and 4.b.2. 


\section{Co-volatility Spillover effects (Group 5)}

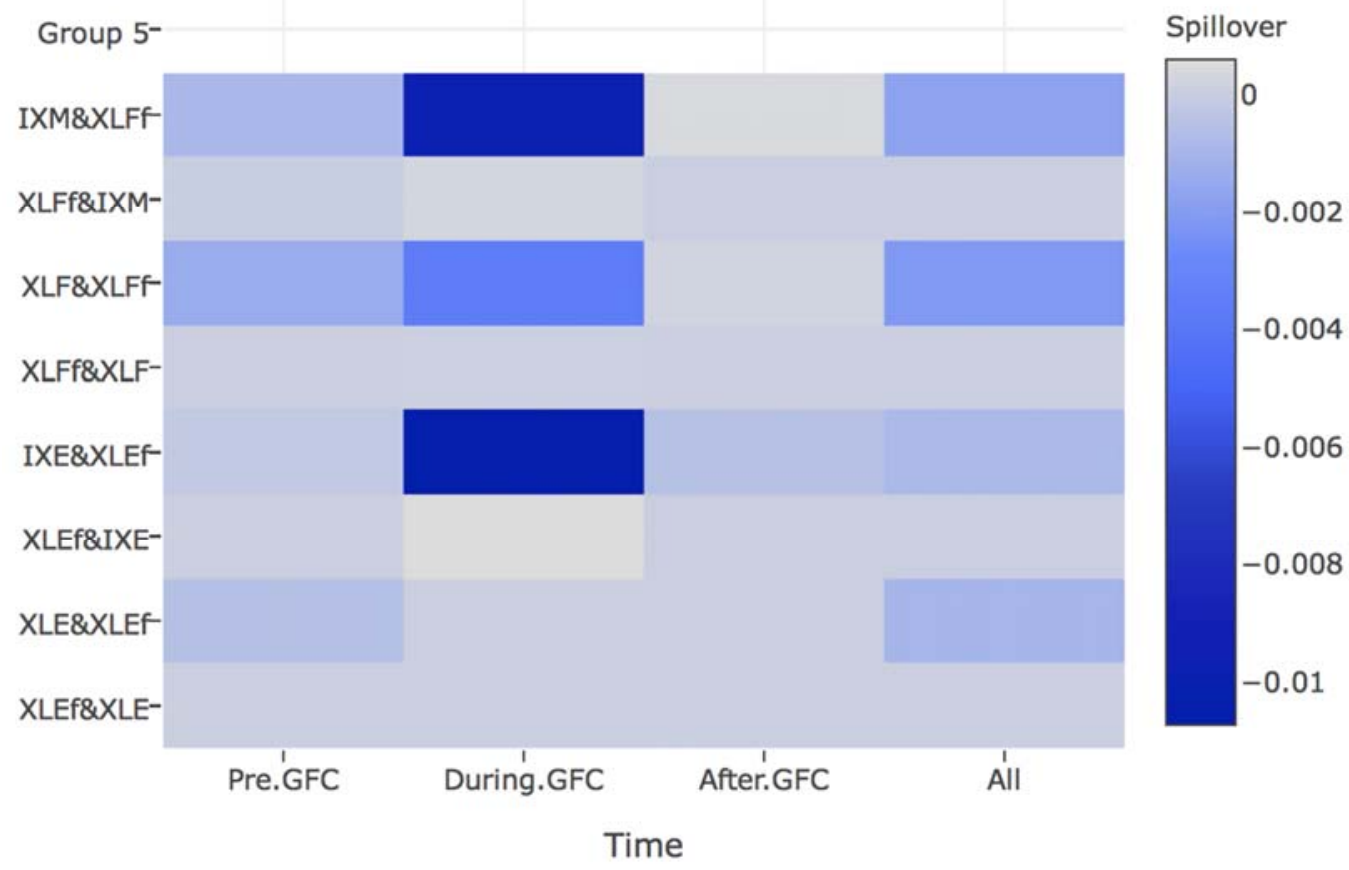

In Group 5, in both before-GFC and the aggregation of all three sub-periods, it was found that in all cases, co-volatility spillovers were statistically significant. For each pair, the magnitude of the spillovers of the futures asset, namely, XLFf (Financial ETF futures) and XLEf (Energy ETF futures), on subsequent co-volatility between itself and its corresponding within-sector spot asset, namely, IXM (Financial Select Sector Index) or XLF (Financial ETF) and IXE (Energy Select Sector Index) or XLE (energy ETF), respectively, was greater than the spillovers of a given spot asset on the same subsequent co-volatility pair.

In Group 5, during-GFC and after-GFC, it was found that in all cases, co-volatility spillovers were statistically significant. In terms of the magnitude of within-sector spot-futures covolatility effects, for each pair, the spillovers of XLFf (Financial ETF futures) on subsequent 
co-volatility between itself and its corresponding within-sector spot asset, namely, IXM (Financial Select Sector Index) or XLF (Financial ETF), was greater than the spillovers of the financial spot asset on the same subsequent co-volatility pair.

With regard to the within energy sector spot-futures co-volatility effect, the spillovers of XLEf (energy ETF futures) on subsequent co-volatility between itself and XLE (Energy ETF), and the spillovers of XLE on the same subsequent co-volatility pair, namely, cases 5.d.1 and 5.d.2, were both significant, albeit, close to zero. However, the spillovers of XLEf (energy ETF futures) on subsequent co-volatility between itself and IXE (Energy index), was greater than the spillovers of the energy index on the same subsequent co-volatility pair, namely, cases 5.c.1 and 5.c.2.

All of the results pertaining to the five groups can be summarized by way of the 6 key findings given below. The terms symmetric and asymmetric, which are defined in terms of absolute values of spillover effects, are used for the first 3 findings. In particular, if a spillover pair is symmetric, it implies similar absolute values of spillover effects in both cases, based on casual empiricism. If a spillover effect pair is asymmetric, it indicates dissimilar absolute values of spillover pairs (in terms of casual empiricism in comparing the point estimates).

1. Asymmetric spillover effects were found in all cases of spot-spot and futures-futures across sectors (see groups 1 and 2).

2. Symmetric spillover effects were found in all cases of spot-spot between the financial ETF and financial index, as well as between the energy ETF and energy index in all periods (see group 4). 
3. Asymmetric spillover effects were found in all cases of spot-futures ETF within sectors. Moreover, in all cases, spillover effects of ETF futures on its co-volatility with the corresponding ETF are stronger than in the reverse case (see group 5).

4. The co-volatility spillovers in all groups over all time periods are statistically significant, except for cases 3.c.1 to 3.d.2 During-GFC.

5. Additionally, with the exception of the insignificant cases, the co-volatility spillovers are stronger During-GFC than for the other time periods (see groups 1, 2, and 4).

6. In terms of the current relationship between the financial and energy sectors, the AfterGFC spillovers are of greater relevance than the spillovers the three sub-periods are combined into a single sample.

\section{Concluding Remarks}

The primary purpose of the paper was to investigate the co-volatility spillovers within and across the US energy and financial sectors in both their spot (namely, IXE, IXM, XLF, and XLE) and futures (namely, XLFf and XLEf) markets, by using "generated regressors" and a multivariate conditional volatility model, namely Diagonal BEKK. The daily data used in the empirical analysis are from $1998 / 12 / 23$ to $2016 / 4 / 22$. The data set was analyzed in its entirety, and also subdivided into three time periods, namely "before-GFC", "during-GFC", "afterGFC".

In Group 1, before and after the Global Financial Crisis, the magnitude of the spillovers of the financial spot asset, namely, IXM (Financial Select Sector Index) or XLF (Financial ETF), on 
subsequent co-volatility between itself and its corresponding energy spot asset, namely, IXE (Energy Select Sector Index) or XLE (energy ETF), was greater than the spillovers of the energy spot asset on the same subsequent co-volatility pair.

However, during the GFC, the pattern changed dramatically. All of the spillovers were stronger, and the spillovers of the financial spot asset on the subsequent co-volatility between itself and its corresponding energy spot asset was the similar to the spillovers of the energy spot asset on the same subsequent co-volatility pair.

Other significant spillover patterns were also found between financial ETF index and energy ETF index in their spot-spot, spot-futures, and futures-futures co-volatility, namely, Groups 2 and 3, when combining all three periods. In terms of the within-sector spot-spot and spotfutures markets, namely, Groups 4 and 5, significant spillovers of ETF futures on subsequent co-volatility between ETF and ETF futures were also found.

It is apparent that there is an intrinsic relationship between the Financial ETF and Energy ETF, both in their spot and futures markets. The energy ETF and financial ETF have statistically significant co-volatility spillovers for all time periods. These empirical results suggest that financial and energy ETFs are suitable for constructing a financial portfolio from an optimal risk management perspective, and also for dynamic hedging purposes. 
Table 1: Data Description

\begin{tabular}{|c|c|c|c|}
\hline $\begin{array}{c}\text { Variable } \\
\text { Name }\end{array}$ & Definitions & Exchange & Source \\
\hline IXM & Financial Select Sector Index & Non-tradable & Bloomberg \\
\hline IXE & Financial Select Sector Index & Non-tradable & Bloomberg \\
\hline XLF & Financial Select Sector SPDR Fund & NYSE & Yahoo Finance \\
\hline XLE & Energy Select Sector SPDR Fund & NYSE & Yahoo Finance \\
\hline XLFf & Financial ETF futures & & $\begin{array}{l}\text { Generated } \\
\text { Regressors }\end{array}$ \\
\hline XLEf & Energy ETF futures & & $\begin{array}{l}\text { Generated } \\
\text { Regressors }\end{array}$ \\
\hline \multicolumn{4}{|c|}{ Constituents of Financial ETF futures (XLFf) } \\
\hline XLF & Financial Select Sector SPDR Fund & NYSE & Yahoo Finance \\
\hline SP1 & Generic $1^{\text {st }}$ S\&P 500 futures & $\mathrm{CME}$ & Bloomberg \\
\hline $\mathrm{Z} 1$ & Generic $1^{\text {st }}$ FTSE 100 futures & LIFFE & Bloomberg \\
\hline \multicolumn{4}{|c|}{ Constituents of Energy ETF futures (XLEf) } \\
\hline XLE & Energy Select Sector SPDR Fund & NYSE & Yahoo Finance \\
\hline CL1 & Generic $1^{\text {st }}$ Crude Oil WTI futures & NYMEX & Bloomberg \\
\hline NG1 & Generic $1^{\text {st }}$ Natural Gas futures & NYMEX & Bloomberg \\
\hline
\end{tabular}


Table 2: Descriptive Statistics (December 22, 1998 - April 22, 2016)

\begin{tabular}{lcrrrrr}
\hline Variables & Mean & Maximum & Minimum & Std. Dev. & Skewness & Kurtosis \\
\hline Return (\%) & & & & & & \\
IXM_Return & -0.00001 & 7.47123 & -8.09431 & 0.85274 & -0.07166 & 18.32649 \\
IXE_Return & 0.00992 & 7.61806 & -7.51765 & 0.75370 & -0.37323 & 12.69031 \\
XLF_Return & 0.00324 & 11.85519 & -8.28167 & 0.86750 & 0.33284 & 24.25198 \\
XLE_Return & 0.01286 & 6.62314 & -6.77485 & 0.75686 & -0.41494 & 12.02135 \\
XLFf_Return & 0.00329 & 11.83412 & -8.26734 & 0.86482 & 0.33368 & 24.23240 \\
XLEf_Return & 0.01290 & 6.61355 & -6.76537 & 0.75571 & -0.41562 & 12.02699 \\
\hline
\end{tabular}

Note: The Jarque-Bera Lagrange Multiplier test is asymptotically chi-squared, and is based on testing skewness and kurtosis against the normal distribution. 
Table 3: Unit Root Tests

\begin{tabular}{lccc}
\hline & \multicolumn{3}{c}{ ADF test } \\
\cline { 2 - 4 } Variables & no trend and intercept & with intercept & with trend and intercept \\
IXM_Return & $-74.8746^{*}$ & $-74.8663^{*}$ & $-74.8584^{*}$ \\
IXE_Return & $-52.3193^{*}$ & $-52.3291^{*}$ & $-52.3299^{*}$ \\
XLF_Return & $-75.4704^{*}$ & $-75.4632^{*}$ & $-75.4554^{*}$ \\
XLE_Return & $-52.2382^{*}$ & $-52.2581^{*}$ & $-52.2579^{*}$ \\
XLFf_Return & $-75.5023^{*}$ & $-75.4951^{*}$ & $-75.4872^{*}$ \\
XLEf_Return & $-52.2497^{*}$ & $-52.2692^{*}$ & $-52.2693^{*}$ \\
\hline & & PP test & \\
\cline { 2 - 4 } Variables & no trend and intercept & with intercept & with trend and intercept \\
IXM_Return & $-76.5683 *$ & $-76.5589^{*}$ & $-76.5513^{*}$ \\
IXE_Return & $-72.0880^{*}$ & $-72.1263^{*}$ & $-72.1402^{*}$ \\
XLF_Return & $-77.5130^{*}$ & $-77.5103^{*}$ & $-77.5032^{*}$ \\
XLE_Return & $-71.8730^{*}$ & $-71.9392^{*}$ & $-71.9946^{*}$ \\
XLFf_Return & $-77.5604^{*}$ & $-77.5577^{*}$ & $-77.5502^{*}$ \\
XLEf_Return & $-71.9054^{*}$ & $-72.0151^{*}$ & $-72.0267^{*}$ \\
\hline
\end{tabular}

Note: ${ }^{*}$ denotes the null hypothesis of a unit root is rejected at the $1 \%$ level. 
Table 4: Estimation of Diagonal Elements of $\boldsymbol{A}$ in BEKK

\begin{tabular}{|c|c|c|c|c|c|c|c|}
\hline \multicolumn{8}{|c|}{ Group 1: Cross-sector spot-spot } \\
\hline Case & Asset 1 & Asset 2 & $A$ & Before-GFC & During-GFC & After-GFC & All \\
\hline \multirow[b]{2}{*}{ 1.a } & \multirow[b]{2}{*}{ IXE } & \multirow[b]{2}{*}{ IXM } & $\mathrm{A} 1(1,1)$ & $0.191 *$ & $0.310^{*}$ & $0.225^{*}$ & $0.227^{*}$ \\
\hline & & & $\mathrm{A} 1(2,2)$ & $0.262 *$ & $0.226^{*}$ & $0.247 *$ & $0.253 *$ \\
\hline \multirow[b]{2}{*}{$1 . b$} & \multirow[b]{2}{*}{ XLE } & \multirow[b]{2}{*}{ XLF } & $\mathrm{A} 1(1,1)$ & $0.202 *$ & $0.290 *$ & $0.224^{*}$ & $0.235^{*}$ \\
\hline & & & $\mathrm{A} 1(2,2)$ & $0.320 *$ & $0.230 *$ & $0.244^{*}$ & $0.272 *$ \\
\hline \multirow[b]{2}{*}{ 1.c } & \multirow[b]{2}{*}{ XLE } & \multirow[b]{2}{*}{ IXM } & $\mathrm{A} 1(1,1)$ & $0.192 *$ & $0.290 *$ & $0.225^{*}$ & $0.227 *$ \\
\hline & & & $\mathrm{A} 1(2,2)$ & $0.261^{*}$ & $0.227^{*}$ & $0.249 *$ & $0.253 *$ \\
\hline \multirow[b]{2}{*}{ 1.d } & \multirow[b]{2}{*}{ IXE } & \multirow[b]{2}{*}{$\mathrm{XLF}$} & $\mathrm{A} 1(1,1)$ & $0.204 *$ & $0.312 *$ & $0.224 *$ & $0.236^{*}$ \\
\hline & & & $\mathrm{A} 1(2,2)$ & $0.323^{*}$ & $0.228 *$ & $0.243^{*}$ & $0.273 *$ \\
\hline \multicolumn{8}{|c|}{ Group 2: Cross-sector futures-futures } \\
\hline Case & Asset 1 & Asset 2 & $A$ & Before-GFC & During-GFC & After-GFC & All \\
\hline \multirow[b]{2}{*}{ 2.a } & \multirow[b]{2}{*}{ XLEf } & \multirow[b]{2}{*}{ XLFf } & $\mathrm{A} 1(1,1)$ & $0.202 *$ & $0.291 *$ & $0.224 *$ & $0.234 *$ \\
\hline & & & $\mathrm{A} 1(2,2)$ & $0.320 *$ & $0.230 *$ & $0.242 *$ & $0.271^{*}$ \\
\hline \multicolumn{8}{|c|}{ Group 3: Cross-sector spot-futures } \\
\hline Case & Asset 1 & Asset 2 & $A$ & Before-GFC & During-GFC & After-GFC & All \\
\hline \multirow[b]{2}{*}{ 3.a } & \multirow[b]{2}{*}{ IXM } & \multirow[b]{2}{*}{ XLEf } & $\mathrm{A} 1(1,1)$ & $0.267^{*}$ & $0.254 *$ & $0.301 *$ & $0.286^{*}$ \\
\hline & & & $\mathrm{A} 1(2,2)$ & $0.178 *$ & $0.272 *$ & $0.188^{*}$ & $0.191 *$ \\
\hline \multirow[b]{2}{*}{ 3.b } & \multirow[b]{2}{*}{ XLF } & \multirow[b]{2}{*}{ XLEf } & $\mathrm{A} 1(1,1)$ & $0.352 *$ & $0.249 *$ & $0.297 *$ & $0.337^{*}$ \\
\hline & & & $\mathrm{A} 1(2,2)$ & $0.174 *$ & $0.275^{*}$ & $0.185^{*}$ & $0.191^{*}$ \\
\hline \multirow[b]{2}{*}{ 3.c } & \multirow[b]{2}{*}{ IXE } & \multirow[b]{2}{*}{ XLFf } & $\mathrm{A} 1(1,1)$ & $0.165^{*}$ & $0.313 *$ & $0.260^{*}$ & $0.234^{*}$ \\
\hline & & & $\mathrm{A} 1(2,2)$ & $0.365^{*}$ & -0.037 & $0.189 *$ & $0.251^{*}$ \\
\hline \multirow[b]{2}{*}{ 3.d } & \multirow[b]{2}{*}{ XLE } & \multirow[b]{2}{*}{ XLFf } & $\mathrm{A} 1(1,1)$ & $0.161^{*}$ & $0.307 *$ & $0.259 *$ & $0.233 *$ \\
\hline & & & $\mathrm{A} 1(2,2)$ & $0.362^{*}$ & -0.041 & $0.187 *$ & $0.250^{*}$ \\
\hline & & & Grol & 4: Within-sec & r spot-spot & & \\
\hline Case & Asset 1 & Asset 2 & $A$ & Before-GFC & During-GFC & After-GFC & All \\
\hline & & & $\mathrm{A} 1(1,1)$ & $0.301 *$ & $0.471 *$ & $0.313^{*}$ & $0.299 *$ \\
\hline 4.a & IXM & XLF & $\mathrm{A} 1(2,2)$ & $0.299 *$ & $0.439 *$ & $0.313^{*}$ & $0.300^{*}$ \\
\hline & & & $\mathrm{A} 1(1,1)$ & $0.187^{*}$ & $0.408 *$ & $0.278^{*}$ & $0.257^{*}$ \\
\hline 4.b & IXE & XLE & $\mathrm{A} 1(2,2)$ & $0.186^{*}$ & $0.403 *$ & $0.271^{*}$ & $0.253^{*}$ \\
\hline
\end{tabular}

Note: * denotes significant at the $1 \%$ level. 
Table 4 (cont.): Estimation of Diagonal Elements of $A$ in BEKK

\begin{tabular}{|c|c|c|c|c|c|c|c|}
\hline \multicolumn{8}{|c|}{ Group 5: Within-sector spot-futures } \\
\hline Case & Asset 1 & Asset 2 & $A$ & Before-GFC & During-GFC & After-GFC & All \\
\hline \multirow[b]{2}{*}{$5 . \mathrm{a}$} & \multirow[b]{2}{*}{ IXM } & \multirow[b]{2}{*}{ XLFf } & $\mathrm{A} 1(1,1)$ & $0.267^{*}$ & $0.272 *$ & $0.256^{*}$ & $0.277^{*}$ \\
\hline & & & $\mathrm{A} 1(2,2)$ & $0.331 *$ & $0.531 *$ & $0.373^{*}$ & $0.321 *$ \\
\hline \multirow[b]{2}{*}{$5 . b$} & \multirow[b]{2}{*}{ XLF } & \multirow[b]{2}{*}{ XLFf } & $\mathrm{A} 1(1,1)$ & $0.321^{*}$ & $0.171 *$ & $0.296^{*}$ & $0.315^{*}$ \\
\hline & & & A1 $(2,2)$ & $0.306^{*}$ & $0.477 *$ & $0.257 *$ & $0.291 *$ \\
\hline \multirow[b]{2}{*}{ 5.c } & \multirow[b]{2}{*}{ IXE } & \multirow[b]{2}{*}{ XLEf } & $\mathrm{A} 1(1,1)$ & $0.211 *$ & $0.274 *$ & $0.233^{*}$ & $0.228 *$ \\
\hline & & & A1 $(2,2)$ & $0.192 *$ & $0.609 *$ & $0.336^{*}$ & $0.304 *$ \\
\hline \multirow[b]{2}{*}{ 5.d } & \multirow[b]{2}{*}{ IXM } & \multirow[b]{2}{*}{ XLEf } & $\mathrm{A} 1(1,1)$ & $0.267 *$ & $0.254 *$ & $0.301 *$ & $0.286^{*}$ \\
\hline & & & $\mathrm{A} 1(2,2)$ & $0.178 *$ & $0.272 *$ & $0.188 *$ & $0.191 *$ \\
\hline
\end{tabular}

Note: * denotes significant at the $1 \%$ level. 
Table 5: Mean Return Shocks

\begin{tabular}{|c|c|c|c|c|c|}
\hline \multicolumn{6}{|c|}{ Group 1: Cross-sector spot-spot } \\
\hline Case & Asset & Before-GFC & During-GFC & After-GFC & All \\
\hline \multirow[b]{2}{*}{ 1.a } & IXE & -0.011204 & -0.071687 & -0.008686 & -0.011357 \\
\hline & IXM & -0.006777 & -0.072454 & 0.001743 & -0.020297 \\
\hline \multirow[b]{2}{*}{$1 . \mathrm{b}$} & XLE & -0.011494 & -0.065577 & -0.007675 & -0.011257 \\
\hline & XLF & -0.007065 & -0.065807 & 0.002071 & -0.020948 \\
\hline \multirow[b]{2}{*}{ 1.c } & XLE & -0.010616 & -0.062126 & -0.008207 & -0.010482 \\
\hline & IXM & -0.006639 & -0.069262 & 0.001767 & -0.019909 \\
\hline \multirow[b]{2}{*}{ 1.d } & IXE & -0.012103 & -0.074886 & -0.008168 & -0.012156 \\
\hline & XLF & -0.007285 & -0.069917 & 0.002027 & -0.02138 \\
\hline \multicolumn{6}{|c|}{ Group 2: Cross-sector futures-futures } \\
\hline Case & Asset & Before-GFC & During-GFC & After-GFC & All \\
\hline \multirow[b]{2}{*}{ 2.a } & XLEf & -0.01166 & -0.067914 & -0.007756 & -0.011694 \\
\hline & XLFf & -0.007 & -0.057135 & 0.002322 & -0.021018 \\
\hline \multicolumn{6}{|c|}{ Group 3: Cross-sector spot-futures } \\
\hline Case & Asset & Before-GFC & During-GFC & After-GFC & All \\
\hline \multirow[b]{2}{*}{ 3.a } & IXM & -0.010596 & -0.08784 & -0.000715 & -0.0222 \\
\hline & XLEf & -0.005352 & -0.043396 & -0.009213 & -0.000729 \\
\hline \multirow[b]{2}{*}{ 3.b } & XLE & -0.012874 & -0.091973 & -0.001053 & -0.024498 \\
\hline & XLEf & -0.005131 & -0.04453 & -0.008712 & -0.000712 \\
\hline \multirow[b]{2}{*}{ 3.c } & IXE & -0.009224 & -0.071131 & -0.009599 & -0.014442 \\
\hline & XLFf & -0.003639 & 0.001534 & 0.006691 & -0.013987 \\
\hline \multirow[b]{2}{*}{ 3.d } & XLE & -0.010088 & -0.064578 & -0.009295 & -0.014803 \\
\hline & XLFf & -0.004424 & 0.000471 & 0.006743 & -0.014104 \\
\hline \multicolumn{6}{|c|}{ Group 4: Within-sector spot-spot } \\
\hline Case & Asset & Before-GFC & During-GFC & After-GFC & All \\
\hline \multirow[b]{2}{*}{ 4.a } & IXM & -0.011165 & -0.08912 & 0.003486 & -0.018308 \\
\hline & $\mathrm{XLF}$ & -0.012522 & -0.086464 & 0.003553 & -0.01781 \\
\hline \multirow[b]{2}{*}{ 4.b } & IXE & -0.007966 & -0.075882 & -0.007843 & -0.014385 \\
\hline & XLE & -0.007481 & -0.072072 & -0.007864 & -0.014581 \\
\hline
\end{tabular}


Table 5 (cont.): Mean Returns Shocks

\begin{tabular}{|c|c|r|r|r|r|}
\hline \multicolumn{7}{|c|}{ Group 5: Within-sector spot-futures } \\
\hline \multirow{3}{*}{ Case } & Asset & Before-GFC & During-GFC & \multicolumn{1}{c|}{ After-GFC } & \multicolumn{1}{c|}{ All } \\
\hline & IXM & -0.010662 & -0.066578 & 0.005485 & -0.020032 \\
\cline { 2 - 7 } & XLFf & -0.000539 & 0.001660 & -0.000476 & $4.67 \mathrm{E}-06$ \\
\hline \multirow{5}{*}{$5 . \mathrm{b}$} & XLF & -0.014975 & -0.045831 & 0.002275 & -0.024073 \\
\cline { 2 - 7 } & XLFf & $2.41 \mathrm{E}-05$ & 0.000424 & $-6.16 \mathrm{E}-05$ & $1.01 \mathrm{E}-05$ \\
\hline \multirow{3}{*}{$5 . \mathrm{c}$} & IXE & -0.005847 & -0.064652 & -0.007429 & -0.012769 \\
\cline { 2 - 7 } & XLEf & 0.000311 & 0.003213 & -0.000369 & -0.000497 \\
\hline \multirow{3}{*}{$5 . \mathrm{d}$} & XLE & -0.009237 & $-6.82 \mathrm{E}-06$ & $-3.66 \mathrm{E}-08$ & -0.016685 \\
\cline { 2 - 7 } & XLEf & $1.10 \mathrm{E}-06$ & $-2.69 \mathrm{E}-05$ & $-3.84 \mathrm{E}-07$ & $-6.85 \mathrm{E}-06$ \\
\hline
\end{tabular}

Note: The mean return shocks are calculated over the respective sample or sub-sample periods. 
Table 6: Mean Co-volatility Spillovers

\begin{tabular}{|c|c|c|c|c|c|c|}
\hline \multicolumn{7}{|c|}{ Group 1: Cross-sector spot-spot spillover effects } \\
\hline Case & Asset $i$ & Asset $j$ & Before-GFC & During-GFC & After-GFC & All \\
\hline 1.a. 1 & IXE & IXM & -0.000561 & -0.005022 & -0.000483 & -0.000652 \\
\hline 1.a. 2 & IXM & IXE & -0.000339 & -0.005076 & 0.000097 & -0.001166 \\
\hline 1.b.1 & XLE & XLF & -0.000743 & -0.004374 & -0.000419 & -0.000720 \\
\hline 1.b. 2 & $\mathrm{XLF}$ & XLE & -0.000457 & -0.004389 & 0.000113 & -0.001339 \\
\hline 1.c. 1 & XLE & IXM & -0.000532 & -0.004090 & -0.000460 & -0.000602 \\
\hline 1.c. 2 & IXM & XLE & -0.000333 & -0.004560 & 0.000099 & -0.001143 \\
\hline 1.d.1 & IXE & XLF & -0.000797 & -0.005327 & -0.000445 & -0.000783 \\
\hline 1.d. 2 & XLF & IXE & -0.000480 & -0.004974 & 0.000110 & -0.001377 \\
\hline \multicolumn{7}{|c|}{ Group 2: Cross-sector futures-futures spillover effects } \\
\hline Case & Asset $i$ & Asset $j$ & Before-GFC & During-GFC & After-GFC & All \\
\hline 2.a.1 & XLEf & XLFf & -0.000754 & -0.004545 & -0.000420 & -0.000742 \\
\hline 2.a. 2 & XLFf & XLEf & -0.000452 & -0.003824 & 0.000126 & -0.001333 \\
\hline \multicolumn{7}{|c|}{ Group 3: Cross-sector spot-futures spillover effects } \\
\hline Case & Asset $i$ & Asset $j$ & Before-GFC & During-GFC & After-GFC & All \\
\hline 3.a.1 & IXM & XLEf & -0.000504 & -0.006069 & -0.000040 & -0.001213 \\
\hline 3.a. 2 & XLEf & IXM & -0.000254 & -0.002998 & -0.000521 & -0.000040 \\
\hline 3.b.1 & XLF & XLEf & -0.000789 & -0.006298 & -0.000058 & -0.001577 \\
\hline 3.b. 2 & XLEf & XLF & -0.000314 & -0.003049 & -0.000479 & -0.000046 \\
\hline 3.c. 1 & IXE & XLFf & -0.000556 & Insignificant & -0.000472 & -0.000848 \\
\hline 3.c. 2 & XLFf & IXE & -0.000219 & Insignificant & 0.000329 & -0.000822 \\
\hline 3.d.1 & XLE & XLFf & -0.000588 & Insignificant & -0.000450 & -0.000862 \\
\hline 3.d. 2 & XLFf & XLE & -0.000258 & Insignificant & 0.000327 & -0.000822 \\
\hline \multicolumn{7}{|c|}{ Group 4: Within-sector spot-spot spillover effects } \\
\hline Case & Asset $i$ & Asset $j$ & Before-GFC & During-GFC & After-GFC & All \\
\hline 4.a.1 & IXM & XLF & -0.001005 & -0.018427 & 0.000342 & -0.001642 \\
\hline 4.a. 2 & $\mathrm{XLF}$ & IXM & -0.001127 & -0.017878 & 0.000348 & -0.001598 \\
\hline 4.b. 1 & IXE & $\mathrm{XLE}$ & -0.000277 & -0.012477 & -0.000591 & -0.000935 \\
\hline 4.b. 2 & XLE & IXE & -0.000260 & -0.011850 & -0.000592 & -0.000948 \\
\hline
\end{tabular}


Table 6 (cont.): Mean Co-volatility Spillovers

\begin{tabular}{|c|c|c|r|r|r|r|}
\hline \multicolumn{7}{|c|}{ Group 5: Within-sector spot-futures spillover effects } \\
\hline Case & Asset $i$ & Asset $j$ & Before-GFC & \multicolumn{1}{c|}{ During-GFC } & \multicolumn{1}{c|}{ After-GFC } & \multicolumn{1}{c|}{ All } \\
\hline 5.a.1 & IXM & XLFf & -0.000942 & -0.009616 & 0.000383 & -0.001781 \\
\hline 5.a.2 & XLFf & IXM & -0.000048 & 0.000240 & -0.000033 & 0.000000 \\
\hline 5.b.1 & XLF & XLFf & -0.001471 & -0.003738 & 0.000173 & -0.002207 \\
\hline 5.b.2 & XLFf & XLF & 0.000002 & 0.000035 & -0.000005 & 0.000001 \\
\hline 5.c.1 & IXE & XLEf & -0.000237 & -0.010788 & -0.000582 & -0.000885 \\
\hline 5.c.2 & XLEf & IXE & 0.000013 & 0.000536 & -0.000029 & -0.000034 \\
\hline 5.d.1 & XLE & XLEf & -0.000615 & -0.000001 & $-2.25 \mathrm{E}-09$ & -0.001069 \\
\hline 5.d.2 & XLEf & XLE & $7.32 \mathrm{E}-08$ & -0.000003 & $-2.36 \mathrm{E}-08$ & $-4.39 \mathrm{E}-07$ \\
\hline
\end{tabular}

Note: Co-volatility Spillover $=\partial Q i j, t / \partial \varepsilon j, t-1=a i{ }^{*} a j j{ }^{*} \varepsilon i, t-1 ;$ mean co-volatility spillovers use the mean return shocks from Table 5. 


\section{References}

Baba, Y., R.F. Engle, D. Kraft and K.F. Kroner (1985), Multivariate Simultaneous Generalized ARCH, Unpublished manuscript, Department of Economics, University of California, San Diego, CA, USA.

Baffes, J., M.A. Kose, F. Ohnsorge and M. Stocker (2015), The Great Plunge in Oil Prices: Causes, Consequences, and Policy Responses, World Bank Report.

Bollerslev, T. (1986), Generalised Autoregressive Conditional Heteroscedasticity, Journal of Econometrics, 31, 307-327.

Bollerslev, T. (1990), Modelling the Coherence in Short-Run Nominal Exchange Rate: A Multivariate Generalized ARCH Approach, Review of Economics and Statistics, 72, 498-505.

Bollerslev, T., R. Engle and J. Wooldridge (1988), A Capital Asset Pricing Model with Time Varying Covariance, Journal of Political Economy, 96, 116-131.

Chang, C.-L. (2015), Modelling a Latent Daily Tourism Financial Conditions Index, International Review of Economics \& Finance, 40(C), 113-126.

Chang, C-L., T-L. Hsieh and M. McAleer (2016), How are VIX and Stock Index ETF Related?,

Tinbergen Institute Discussion Paper 16-010/III, Tinbergen Institute, Amsterdam and Rotterdam, The Netherlands.

Chang C.-L. and Y.-P. Ke (2014), Testing Price Pressure, Information, Feedback Trading, and Smoothing Effects for Energy Exchange Traded Funds, Annals of Financial Economics, 9(2), $1-26$.

Chang, C.-L., Y.-Y. Li and M. McAleer (2015), Volatility Spillovers between Energy and Agricultural Markets: A Critical Appraisal of Theory and Practice, Tinbergen Institute Discussion Papers 15-077/III, Tinbergen Institute. 
Chang, C.-L., M. McAleer and Y.-A. Wang (2016), Modelling Volatility Spillovers for Bioethanol, Sugarcane and Corn, Tinbergen Institute Discussion Papers 16-014/III, Tinbergen Institute.

Chen J.-H. and C.-Y. Huang (2010), An Analysis of the Spillover Effects of Exchange Traded Funds, Applied Economics, 42(9), 1155-1168.

Engle, R.F. (1982), Autoregressive Conditional Heteroscedasticity with Estimates of the Variance of United Kingdom Inflation, Econometrica, 50, 987-1007.

Engle, R. (2002), Dynamic Conditional Correlation: A Simple Class of Multivariate Generalized Autoregressive Conditional Hereoskedasticity Models, Journal of Business and Economic Statistics, 20, 339-350.

Engle, R.F. and K.F. Kroner (1995), Multivariate Simultaneous Generalized ARCH, Econometric Theory, 11(1), 122-150.

Fiebig, D.G., M. McAleer and R. Bartels (1992), Properties of Ordinary Least Squares Estimators in Regression Models with Non-Spherical Disturbances, Journal of Econometrics, $54,321-334$.

Jeantheau, T. (1998), Strong Consistency of Estimators for Multivariate ARCH Models, Econometric Theory, 14, 70-86.

Ling, S. and M. McAleer (2003), Asymptotic Theory for a Vector ARMA-GARCH Model, Econometric Theory, 19, 278-308.

McAleer, M. (1992), The Rao-Zyskind Condition, Kruskal's Theorem and Ordinary Least Squares, Economic Record, 68, 65-72.

McAleer, M. (2005), Automated Inference and Learning in Modeling Financial Volatility, Econometric Theory, 21(1), 232-261.

McAleer, M. (2014), A One Line Derivation of EGARCH, Econometrics, 2, 92-97. 
McAleer, M., F. Chan, S. Hoti and O. Lieberman (2008), Generalized Autoregressive Conditional Correlation, Econometric Theory, 24(6), 1554-1583.

McAleer, M., S. Hoti and F. Chan (2009), Structure and Asymptotic Theory for Multivariate Asymmetric Conditional Volatility, Econometric Reviews, 28, 422-440.

McAleer. M., J.-A. Jimenez-Martin and T. Perez-Amaral (2013), Has the Basel Accord Improved Risk Management During the Global Financial Crisis?, North American Journal of Economics and Finance, 26(C), 250-265.

McAleer, M. and C.R. McKenzie (1991), When are Two-Step Estimators Efficient?, Econometric Reviews, 10, 235-252.

McLannahan, B. and A. Gray (2016, January 15), Big US Banks Reveal Oil Price Damage, Financial Times.

Olson, B., E. Glazer and M. Jarzemsky (2016, March 24), Coming to the Oil Patch: Bad Loans to Outnumber the Good, The Wall Street Journal.

Smith, G. (2014, July 4), U.S. Seen as Biggest Oil Producer After Overtaking Saudi, Bloomberg.

Tsay, R.S. (1987), Conditional Heteroscedastic Time Series Models, Journal of the American Statistical Association, 82, 590-604.

Tse, Y.K. and A.K.C. Tsui (2002), A Multivariate GARCH Model with Time-Varying Correlations, Journal of Business and Economic Statistics, 20, 351-362.

Van Vactor, S.A. (2009, January 1), Financial Crisis Impacts Energy Industry, Oil and Gas Financial Journal. 